Aus der Abteilung Anatomie und Zellbiologie

(Komm. Leiter: Prof. Dr. rer. nat. J. Wilting)

im Zentrum Anatomie

der Medizinischen Fakultät der Universität Göttingen

\title{
Immunhistologische Untersuchungen venöser Malformationen
}

\author{
INAUGURAL - DISSERTATION \\ zur Erlangung des Doktorgrades \\ der Medizinischen Fakultät \\ der Georg-August-Universität zu Göttingen
}

vorgelegt von

Katja Bartnick

aus

Hamburg

Göttingen 2010 
Dekan: Prof. Dr. med. C. Frömmel

I. Berichtserstatter: Prof. Dr. rer. nat. Wilting

II. Berichtserstatter/in: Prof. Dr. med. Schöndube

III. Berichtserstatter/in: Prof. Dr. rer. nat. Virsik-Köpp

Tag der mündlichen Prüfung: 26. September 2011 


\section{Inhaltsverzeichnis}

1 Einleitung.........................................................................................................................

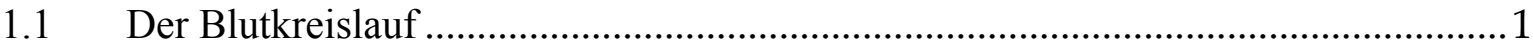

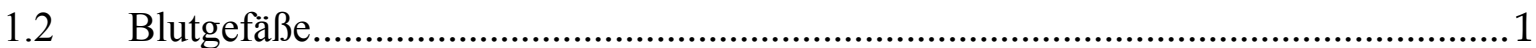

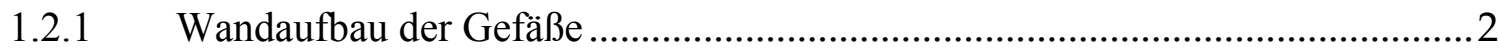

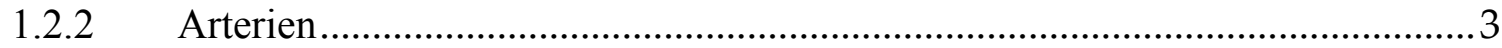

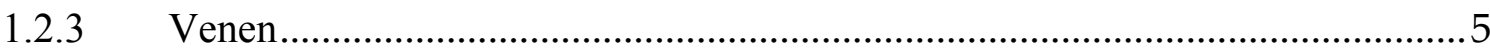

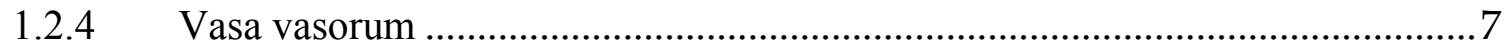

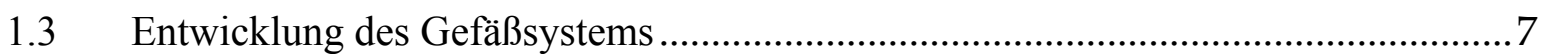

1.3.1 Regulation von Vaskulogenese und Angiogenese ...................................... 10

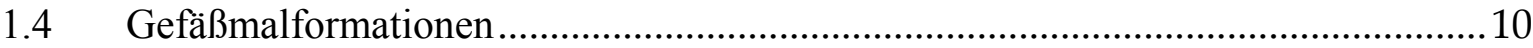

1.4.1 Vorwiegend kapilläre Malformationen .................................................... 11

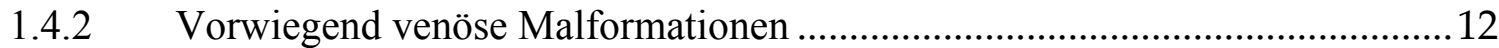

1.4.3 Vorwiegend lymphatische Malformationen .................................................14

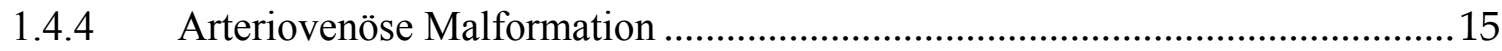

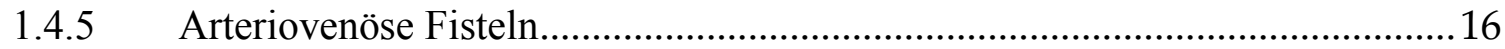

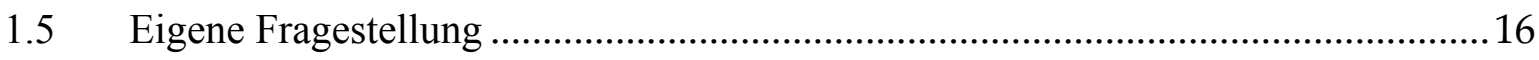

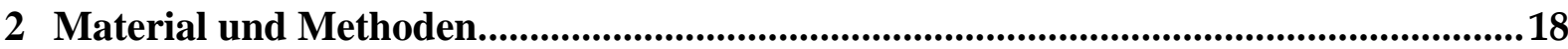

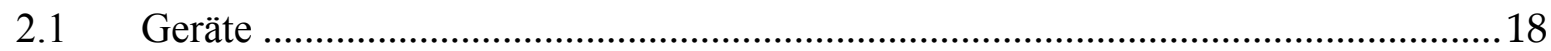

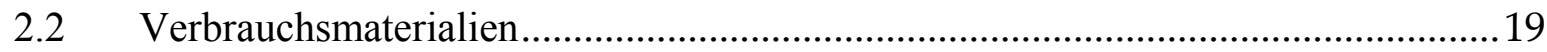

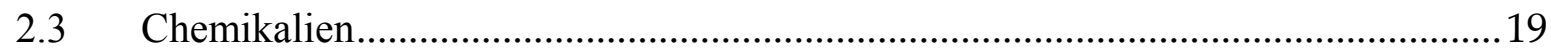

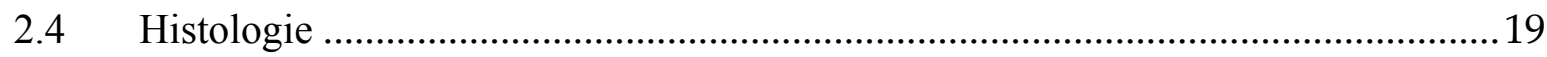

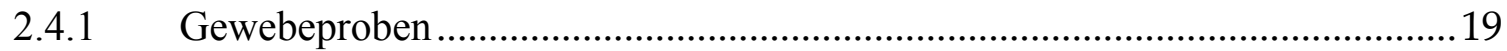

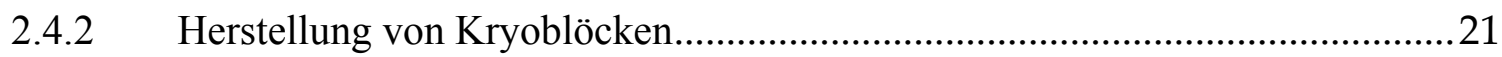




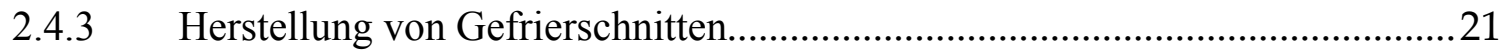

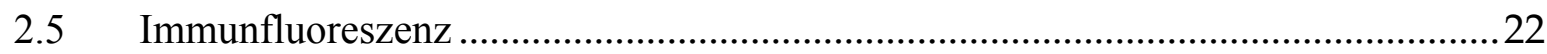

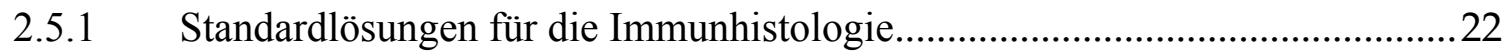

2.5.2 Antikörper für die Immunfluoreszenz .....................................................22

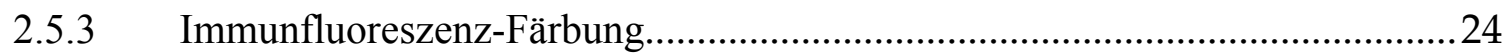

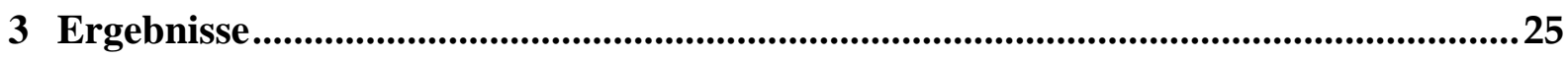

Immunfluoreszenz-Einzelfärbungen ......................................................... 25

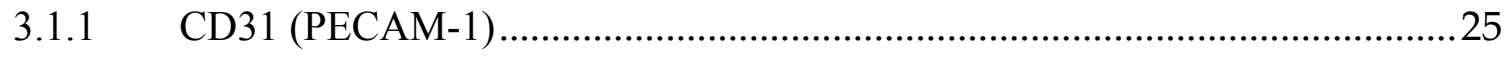

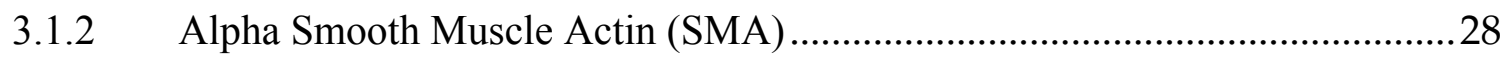

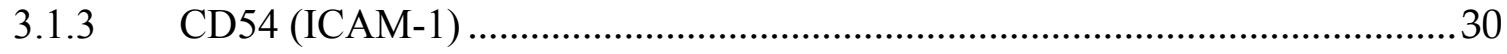

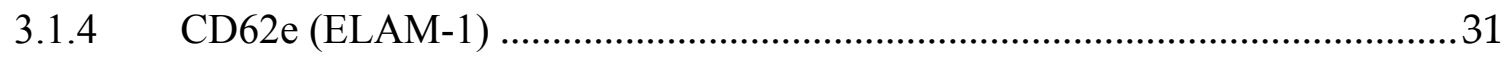

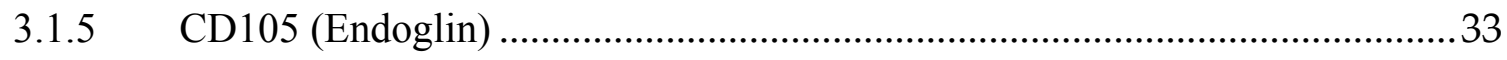

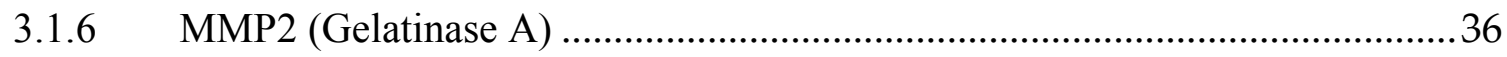

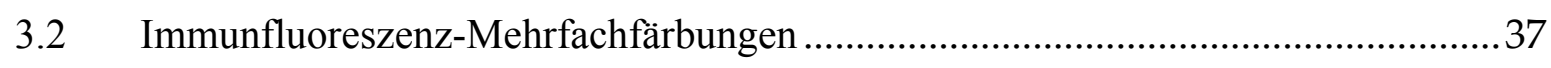

3.2.1 Doppelfärbung mit PAL-E und EphB4 …....................................................

3.2.2 Doppelfärbung mit PAL-E und EphrinB2 sowie CD31 und EphrinB2 ...........42

3.2.3 Mehrfachfärbung mit CD31, Dapi und EphB2 ….....................................44

3.3 Zusammenfassung der Ergebnisse ............................................................. 47

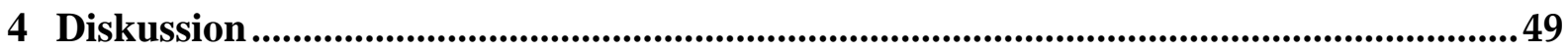

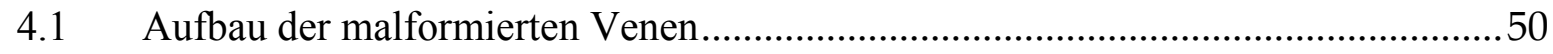

Entzündungszeichen in den venösen Malformationen ...........................................50

4.3 Arterialisierung in den venösen Malformationen .............................................52

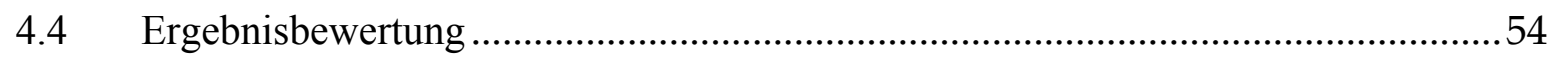

5 Zusammenfassung ..........................................................................................................55 


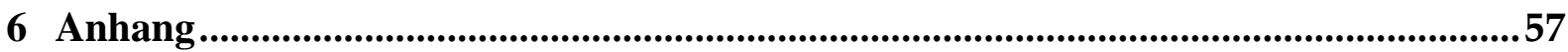

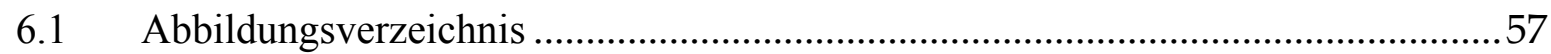

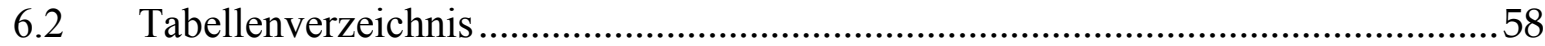

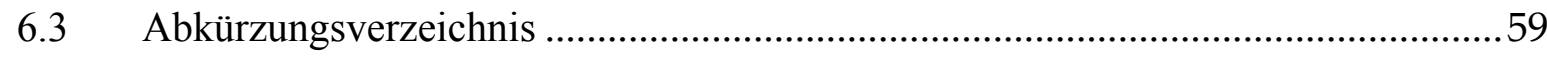

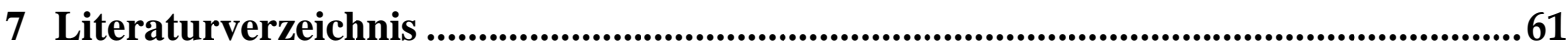




\section{Einleitung}

\subsection{Der Blutkreislauf}

Der humane Blutkreislauf ist, mit Ausnahmen in Milz und Plazenta, ein geschlossenes System, in dem physiologisch im Körper Blut transportiert wird. Dieses System besteht aus dem Herzen, das die zentrale Pumpfunktion übernimmt, und den Blutgefäßen, in denen das Blut zu den Zielorganen befördert wird. Es wird auch als kardiovaskuläres System bezeichnet.

\subsection{Blutgefäße}

Blutgefäße werden aufgrund ihres Aufbaus und ihrer Funktion in verschiedene Typen unterteilt. Im menschlichen Blutkreislauf gibt es Arterien, die das Blut vom Herzen weg transportieren, und Venen, die das Blut von der Peripherie zum Herzen transportieren. Das Herz bildet die zentrale Pumpe, welche durch Druck das Blut in die Gefäße befördert und damit die Richtung des Blutstroms durch den Körper vorgibt. Zwischen dem venösen und arteriellen Stromgebiet liegen Gefäße, die der Mikrozirkulation angehören. Der Durchmesser wird, ausgehend vom Herzen, immer kleiner. Arteriolen führen das Blut dann in den verschiedenen Geweben $\mathrm{zu}$ den Kapillaren. Hier finden der Gas- und Stoffaustausch statt. An die Kapillaren schließen sich die Venolen an, die dann zu den größerlumigen Venen werden, in denen das Blut zurück zum Herzen befördert wird.

Man unterscheidet den großen und den kleinen Blutkreislauf, in denen das Herz das Koordinationszentrum bildet. Das Herz, ein muskulöses Hohlorgan, besteht aus zwei Vorhöfen und zwei Kammern. Das Blut aus der Körperperipherie gelangt zunächst in den rechten Vorhof und dann in die rechte Herzkammer. Von dort gelangt es in den kleinen Kreislauf und damit in die Lunge. In den Kapillaren der Lunge finden die Abgabe von Kohlendioxid und die Aufnahme von Sauerstoff statt. Schließlich wird das Blut über die Venae pulmonales 
zurück in das Herz befördert. Zuerst gelangt das nun sauerstoffreiche Blut in den linken Vorhof, dann in die linke Herzkammer und von dort, mithilfe der Pumpkraft des Herzens, in die Körperperipherie, um die Zielorgane mit Sauerstoff und Nährstoffen $\mathrm{zu}$ versorgen und Abbauprodukte abzutransportieren. Durch regelmäßige Kontraktion und Erschlaffung des Herzens, die Koordination der Vorhöfe und Kammern und die Elastizität der Gefäße, wird der physiologische Blutkreislauf aufrechterhalten (Schiebler und Korf 2007; Baum 2004; Silbernagl und Despopoulos 2007).

\section{Wandaufbau der Gefäße}

Die Gefäße des menschlichen Blutkreislaufes haben im Wesentlichen einen gleichartigen Wandaufbau. Die einzelnen Modifikationen der Gefäßwand kommen durch die unterschiedlichen Funktionen der Gefäße zu Stande. Das venöse System ist zum Beispiel anders strukturiert als das arterielle System oder das Kapillarsystem, da es anderen Bedingungen ausgesetzt ist und andere Funktionen erfüllt. Dazu gibt es noch Unterschiede in den einzelnen Organen. Es gibt keine scharfe Trennung der einzelnen Abschnitte untereinander, es ist vielmehr ein fließender Übergang zu beobachten. Der Aufbau der Arterien und Venen besteht in der Regel aus drei Schichten:

1. Die Tunica interna (Intima) bildet die innere Schicht des Gefäßes. Sie besteht aus flachem, einschichtigem Plattenepithel, dem so genannten Endothel. Das Endothel bildet die Innenfläche des Gefäßes zum Lumen hin und somit die Grenze zum durchfließenden Blut. Das Endothel liegt einer Basalmembran an. Unmittelbar darunter befindet sich das Stratum subendotheliale. Das Stratum subendotheliale ist ein lockeres Bindegewebe, welches aus Fibroblasten, Abwehrzellen und glatten Muskelzellen besteht. Die Tunica interna sorgt für einen optimalen Gas- und Stoffaustausch zwischen Blut und der Gefäßwand. Die Membrana elastica 
interna bildet aus elastischen Fasern die Grenze zur darunter liegenden Tunica media.

2. Die Tunica media (Media) ist die mittlere Schicht des Gefäßes. Sie besteht aus glatten Muskelzellen, sowie Kollagenfaser und elastischen Fasern, die sich ringförmig anordnen. Die Tunica media reguliert die Weite des Gefäßes durch Muskelkontraktionen. In größeren Gefäßen kann eine Lamina elastica externa vorkommen, welche die Grenze zur Tunica adventitia darstellt. Venen besitzen einen hohen Anteil an Bindegewebe in der Tunica media.

3. Die Tunica externa (Adventitia) bildet die äußere Schicht der Gefäßwand. Sie besteht aus einem lockeren Bindegewebsgeflecht, welches kollagene Fasern und einen hohen Anteil an elastischen Fasern enthält. Das lockere Bindegewebe der Tunica adventitia geht in das Stroma des Organs über, in welches das Gefäß eingebettet ist (Junqueira und Carneiro 2004; Schiebler und Korf 2007; Baum 2004; Silbernagl und Despopoulos 2007).

\section{Arterien}

Arterien transportieren vom Herzen das zumeist sauerstoff- und nährstoffreiche Blut $\mathrm{zu}$ den Organen und regulieren maßgeblich über eine nervale und hormonelle Steuerung die Durchblutung eines Organs oder eines Organabschnitts. Es gibt drei verschiedene Arten arterieller Gefäße: Arterien vom elastischen Typ, Arterien vom muskulären Typ und Arteriolen.

\subsubsection{Arterien vom elastischen Typ}

$\mathrm{Zu}$ dieser Sorte von Arterien gehören die Aorta und die von ihr abzweigenden arteriellen herznahen Äste. Die Intima ist bei diesen Gefäßen meistens dicker als bei anderen Gefäßen, da das Stratum endotheliale mehr retikuläre Fasern beinhaltet. In der Tunica media dieser Gefäße befindet sich ein hoher Anteil an 
konzentrisch angeordneten elastischen Fasernetzen und metabolischen, glatten Muskelzellen. Die Aorta eines Erwachsenen kann bis zu 70 Lamellen dieser glatten Muskelzellen enthalten (Junqueira und Carneiro 2004). Die Tunica adventitia enthält elastische Fasern, Kollagenfasern, Nerven und Vasa vasorum.

Durch den hohen Anteil an elastischen Fasern sind die herznahen Gefäße in der Lage, den pulsativen und diskontinuierlichen Blutstrom des Herzens in einen nahezu kontinuierlichen Blutstrom für die Peripherie umzuwandeln. Dies ist die so genannte Windkesselfunktion.

\subsubsection{Arterien vom muskulären Typ}

$\mathrm{Zu}$ dieser Sorte von Arterien gehören die mittleren bis kleinen Arterien. Die Tunica media besitzt bei diesen Gefäßen eine ausgeprägte glatte Muskulatur. Diese Arterien sind in der Lage, dem Druck, der durch die Pumpleistung des Herzens entsteht, standzuhalten und sich im herznahen Bereich bei Bedarf zu weiten. Bei abfallenden Drücken können sich die mittleren bis kleinen Arterien zum Ausgleich kontrahieren. Diese Vasokonstriktion dient dazu, den Blutdruck stabil zu halten.

\subsubsection{Arteriolen}

Die Arteriolen bestehen aus einer bis zwei Schichten glatter Muskelzellen in ihrer Tunica media. Sie haben einen sehr dünnen Schichtaufbau und einen Durchmesser von 30-40 $\mu \mathrm{m}$ (Junqueira und Carneiro 2004). Dabei sind sie sehr kontraktil und können bei Bedarf das komplette Gefäß verschließen. Dadurch kontrollieren sie den Blutzufluss zu den einzelnen Geweben. Die Arteriolen gehen dann über in die Kapillaren.

\subsubsection{Kapillaren}

Die feinen Kapillaren sind Haargefäße, die bis zu einem Millimeter lang und einen Durchmesser von 5 bis $15 \mu$ m haben können (Schiebler und Korf 2007). Sie 
sind die Verbindung zwischen dem arteriellen und venösen System. Die Gefäßwände sind bei den Kapillaren sehr dünn, damit hier ein optimaler Gasund Nährstoffaustausch zwischen Blut und Gewebe stattfinden kann. Es gibt unterschiedliche Varianten von Kapillaren: kontinuierliche, gefensterte und diskontinuierliche (Schiebler und Korf 2007).

\section{Venen}

Venen nehmen das Blut aus dem Kapillarbett auf. Sie leiten es über kleinlumige Venolen, die sich zu kleineren bis mittelgroßen Venen und dann zu den großen Venen vereinen, zurück zum Herzen. Dadurch, dass sie einen sehr großen Gesamtquerschnitt haben, beinhaltet das venöse System 75-80 \% des gesamten Blutvolumens (Baum 2004). Diese Gefäße werden deshalb auch Kapazitätsgefäße genannt. Der große Gesamtquerschnitt hat zur Folge, dass die Venen einen geringeren Strömungswiderstand haben, so dass schon ein niedriger, mittlerer Druck ausreicht, um das Blut zurück zum Herzen zu befördern (Baum 2004).

\subsubsection{Venolen}

Die Venolen gehen direkt aus dem Kapillarbett hervor und unterscheiden sich kaum von dem Aufbau der Kapillaren. Sie werden deshalb ebenfalls zu den nutritiven Gefäßen gezählt, die im Gewebe für Sauerstoff- und Nährstoffaustausch sorgen. Ebenfalls kennzeichnend für Venolen ist die Leukodiapedese, bei der die Leukozyten in das umliegende Gewebe einwandern können. Venolen haben einen durchschnittlich erweiterten Durchmesser des Lumens im Vergleich $\mathrm{zu}$ den Kapillaren von 8-30 $\mu \mathrm{m}$ (Schiebler und Korf 2007). Die sich daran anschließenden Sammelvenolen können einen Durchmesser von bis zu 0,5 mm haben und weisen schon den dreischichtigen, oben beschriebenen Wandaufbau auf (Junqueira und Carneiro 
2004). Die Tunica media besteht zunächst aus dünnen und vereinzelten Schichten von glatten Muskelzellen und die Tunica externa ist meist deutlicher ausgeprägt.

\subsubsection{Kleine und mittelgroße Venen}

Diese Venen sind meist weitlumiger und dünnwandiger als Arterien und erreichen einen Durchmesser von 0,5 mm bis zu $9 \mathrm{~mm}$ (Junqueira und Carneiro 2004). Die Tunica interna weist teilweise schon ein Stratum subendotheliale auf und die Tunica media besteht aus mehreren Lagen von glatten Muskelzellen, Kollagenfasern und elastischen Fasern. Die Muskelzellen ordnen sich hier in gebündelter Form in der Längsachse oder schräg dazu an und sind damit im Vergleich zu den Arterien nicht konzentrisch um die Längsachse des Gefäßes ausgerichtet. Die Tunica externa ist, wie bei den Venolen, deutlich ausgebildet. Im Unterschied zu den Arterien haben die Venen in der Regel dünnere Wände und einen größeren Durchmesser als Arterien.

Um den Rückfluss im Körper zu unterstützen, gibt es in den Venen so genannte Venenklappen. Das sind Tunica-interna-Duplikaturen, die bei Muskelkontraktion, zum Beispiel in den Beinen, das Blut nur herzwärts befördern und ein Zurücksacken des Blutes verhindern.

Mittelgroße und große Venen verlaufen meist parallel zu den großen Arterien. Zudem unterscheidet man oberflächliche epifasziale Venen, die in der Haut liegen und dort ein Netzwerk bilden und tiefe Venen, die in der Skelettmuskulatur liegen. Sie sind durch Perforansvenen miteinander verbunden, wobei das Blut von den oberflächlichen Venen $\mathrm{zu}$ den tiefer gelegenen Venen strömt. Der Blutfluss wird in den Venen von außen wirkenden Kräften, wie Muskelkontraktionen der Skelettmuskulatur und die Vasokonstriktion und -dilatation anliegender Arterien beeinflusst. Diese wirken als Venenpumpen. 


\subsubsection{Große Venen}

Die Tunica media der großen Venen ist meist sehr dünn mit wenigen Schichten glatter Muskelfasern und reichlich kollagenen und auch elastischen Fasern. Die Anzahl der Muskellamellen variiert nach dem vorherrschenden hydrostatischen Druck und ist somit in den Beinen ausgeprägter als in den Hirn versorgenden Venen. Die Tunica interna ist bei den großen Venen meist deutlicher ausgeprägt als bei den mittelgroßen Venen. Die herznahen Venen besitzen in der Adventitia Längsmuskelzüge, da diese Venen bei der Diastole ständig gedehnt werden.

\section{Vasa vasorum}

Die Wanddicke der verschiedenen Gefäßarten reicht von $100 \mu \mathrm{m}$ bis $2 \mathrm{~mm}$ bei der Aorta und bis 1,5 mm bei den Hohlvenen (Junqueira und Carneiro 2004). Die Ernährung der äußeren Zellen der Gefäßwände ist nicht ausreichend per Diffusion der Nährstoffe vom Lumen her gewährleistet. Diese Aufgabe erfüllen die Vasa vasorum, die in der Tunica externa und manchmal noch in der äußeren Schicht der Tunica media ein Geflecht aus Gefäßen bilden. Dadurch werden die äußeren Gefäßschichten mit Nährstoffen und Sauerstoff versorgt. In den größeren Venen befindet sich aufgrund der Sauerstoff- und Nährstoffarmut im venösen Blut eine höhere Anzahl an Vasa vasorum als in den arteriellen Gefäßen (Junqueira und Carneiro 2004; Schiebler und Korf 2007; Gössl et al. 2003).

\subsection{Entwicklung des Gefäßsystems}

Das Herz und die Gefäße entwickeln sich aus dem Mesoderm, eines der drei Keimblätter, die bei der Gastrulation entstehen. Man unterscheidet Vaskulogenese und Angiogenese. Bei der Vaskulogenese entstehen aus Mesodermzellen, über die Vorstufe der Hämangioblasten und Angioblasten, einschichtige Blutgefäße während der Embryonalentwicklung (Seval et al. 2008; Joussen et al. 2003; Geva et al. 2002; Kaufmann et al. 2000; Tallquist et al. 1999). 
Die Angiogenese beschreibt hingegen das Aussprossen neuer Gefäße aus vorher bestehenden Gefäßen sowie die Spaltung bestehender Gefäße (Moore et al. 2007; Juhasz-Böss et al. 2006; Plendl 2000).

Die frühe tubuläre Herzanlage beginnt schon in der dritten Embryonalwoche erste Kontraktionen auszuüben und ist mit den Gefäßen das erste funktionstüchtige Organsystem des Embryos. Somit wird bereits eine sichere Versorgung mit Sauerstoff und Nährstoffen, sowie der Abtransport von Kohlendioxid und Abfallstoffen gewährleistet (Hawighorst 2002; Moore et al. 2007; Kroll und Waltenberger 2000).

Bei der Entwicklung des Gefäßsystems wird beim menschlichen Embryo und bei Säugetierembryonen zwischen extra- und intraembryonaler Gefäßentwicklung unterschieden. Die Gefäßbildung beginnt in der 3. Entwicklungswoche (Schiebler und Korf 2007). Die extraembryonale Gefäßentwicklung nimmt ihren Ausgangspunkt im Mesoderm von Dottersack, Haftstiel und Chorion. Aus den sich daraus formierenden Blutinseln entstehen das Gefäßendothel und erste Blutzellen (Schiebler und Korf 2007). In den Blutinseln fließen die Interzellularspalten zusammen und formieren Hohlräume, in denen die Angioblasten die Form der Endothelzellen annehmen (Folkman und Shing 1992; Moore et al. 2007). Benachbarte Hohlräume fusionieren miteinander und bilden ein vaskuläres Netzwerk (Kroll und Waltenberger 2000; Poole und Coffin 1989; Risau 1997). Aus diesen sich formierenden Blutgefäßen sprießen einzelne Kapillaren $\mathrm{zu}$ den sich entwickelnden Organanlagen aus. Das umliegende Mesenchym bildet die Zellen der Gefäßwände, also Bindegewebe und glatte Muskulatur (Moore et al. 2007). Das extraembryonale Gefäßnetz stellt den Anschluss zu der sich entwickelnden Plazenta her (Schiebler und Korf 2007). 
Die intraembryonale Gefäßentwicklung verläuft manchmal ebenfalls über Blutinseln. Cluster angiogener Zellen vereinigen sich miteinander wie oben beschrieben. Sie werden zum Beispiel über Arteriae und Venae umbilicales mit den extraembryonalen Gefäßen verbunden (Schiebler und Korf 2007). Zusätzlich entstehen Endothelzellen auch aus Angioblasten, die keine hämatogene Potenz besitzen. Zunächst besteht noch kein histologischer Unterschied zwischen Venen und Arterien. Dieser entwickelt sich erst im Laufe der Embryogenese und Organogenese (Moore et al. 2007). Man nahm ursprünglich an, dass die Vaskulogenese nur in der Embryonalentwicklung zu beobachten ist. Diese These konnte aber widerlegt werden, zum Beispiel anhand der Tumorangiogenese. Hier findet eine Kombination aus Vaskulogenese und Angiogenese statt (Joussen et al. 2003).

Neben der Vaskulogenese entwickeln sich Gefäße auch über den Mechanismus der Angiogenese in der Embryonalentwicklung (Risau 1997). Zunächst dilatiert ein vorhandenes Gefäß und die Permeabilität wird erhöht. Die Endothelzellen werden destabilisiert und das umliegende Gewebe wird über sezernierte Matrixmetalloproteasen (MMP) proteolytisch zersetzt. Zudem wird eine Extrazellulärmatrix aufgebaut, in die die neuen Gefäße sprossen können (Terman and Stoletov 2001). Die Zellkontakte der Endothelzellen und Perizyten des Gefäßes werden gelöst und die Basalmembran proteolytisch abgebaut. Nun proliferieren die Endothelzellen, wandern aus und bilden ein Lumen. Sie differenzieren aus und verbinden sich mit anderen Gefäßen (Burri et al. 2004; Risau 1997; Folkman und Shing 1992).

Die Angiogenese kommt beim Adulten physiologisch beim Haarwechsel, im Endometrium während der Proliferationsphase sowie bei der Wundheilung vor (Wulff et al. 2003; Hawighorst 2002; Gordon et al. 1995; Iruela-Arispe und Dvorak 1997). Hingegen entstehen pathologische Gefäße bei Tumorwachstum, 
rheumatoider Arthritis und Atherosklerose (Saaristo et al. 2000; Folkman 1996; Bergers und Benjamin 2003; Shibuya 2008; Carmeliet and Jain 2000).

\section{Regulation von Vaskulogenese und Angiogenese}

Die Induktion von Angiogenese und Vaskulogenese erfolgt über verschiedene, komplexe Mechanismen. Die bedeutendste angiogene Wirkung hat der vaskuläre endotheliale Wachstumsfaktor VEGF, der vom Epithel des Dottersacks, also dem Entoderm, gebildet wird. Dieser bindet an VEGFRezeptor-2 der Angioblasten (Benninghoff 2004; Terman und Stoletov 2001; Petrova et al. 1999). Außerdem kommt noch eine Reihe anderer stimulativer Faktoren hinzu, wie der fibroblastische Wachstumsfaktor FGF-2 und die Angiopoetine mit ihren dazugehörigen Rezeptoren, die die Proliferation der Endothelzellen induzieren (Ornitz und Itoh 2001; Davis et al. 1996; Nugent and Iozzo 2000). Darüber hinaus gibt es Inhibitoren wie Thrombospondin, Angiostatin und Endostatin (O'Reilly et al 1994; Roberts 1996; O'Reilly et al. 1997). Eine ausführlichere Darstellung folgt in der Diskussion.

\subsection{Gefäßmalformationen}

Nicht immer entwickeln sich Gefäße normal. Im Gegenteil, Gefäßfehlbildungen sind bei Neugeborenen sehr häufig zu beobachten. Man unterscheidet bei den vaskulären Anomalien zwischen angeborenen Gefäßmalformationen und vaskulären Tumoren.

Gefäßmalformationen resultieren aus einer Fehlregulation der Embryogenese und stellen sich als dysmorphe Gefäßkanäle dar (Burrows et al. 1998; Kohout et al. 1998). Sie sind bei der Geburt bereits vorhanden und vergrößern sich dann proportional mit dem Körperwachstum (Lee et al. 2007). Gefäßmalformationen werden entsprechend der „Hamburger Klassifikation“ von 1989 eingeteilt in: vorwiegend arterielle Malformationen, vorwiegend venöse Malformationen, arteriovenöse Malformationen mit AV-Fisteln, lymphatische Malformationen 
und kombinierte vaskuläre Malformationen (Belov 1989; Belov 1990; Belov 1993). Jede Malformation ist subklassifiziert in Bezug auf Lage und Größe in eine trunkuläre oder eine extratrunkuläre Form (Belov 1990). Die klinischen Symptome sind abhängig von individuellen Faktoren und dem Zeitpunkt des Arrests der Gefäßentwicklung. Die trunkulären Malformationen entstehen aus Dysplasien großer Leitungsbahnen. Die extratrunkulären entstehen aus dem embryonalen Kapillarnetz. Die Unterscheidung von trunkulären und extratrunkulären Malformationen ermöglicht dem Kliniker den Krankheitsverlauf und die Rezidivrate zu prognostizieren (Lee et al. 2007).

Man unterscheidet bei Gefäßmalformationen ebenfalls zwischen langsam und schnell durchflossenen Läsionen („low flow“, „high flow“). Zu den „low-flow“Läsionen zählt man die kapillären, venösen und lymphatischen Malformationen (Enjolras 1997). Die „high-flow“-Läsionen bestehen aus den arteriovenösen Malformationen, arteriovenösen Fisteln und deren Mischformen.

\section{Vorwiegend kapilläre Malformationen}

Kapilläre Malformationen wurden als erstes von John Mulliken beschrieben (Fishman und Mulliken 1998). Mulliken ging zunächst davon aus, dass es sich hierbei um das so genannte „Feuermal“ oder den „Portweinfleck“ handelte. Die Definition kapillärer Malformationen hat sich jedoch weiter ausgedehnt. Mittlerweile wird der Begriff der kapillären Gefäßmalformation als Oberbegriff verwendet für eine Gruppe verschiedener, vaskulärer Anomalien zu denen die teleangiektatischen Nävi (Naevus flammeus, Naevus roseus, Cutis marmorata teleangiectatica congenita und Naevus anaemicus) und die Nicht-Nävi wie der Unna-Fleck „Storchenbiss“ und Teleangiektasien des Morbus Rendu-Osler gehören (Happle 2006).

Der Naevus flammeus (umgs: Feuermal) ist ein Beispiel für eine Form der angeborenen kapillären Malformationen. Hierbei handelt es sich um eine 
Gefäßaussackung in der Kutis. Man unterteilt die Läsionen in die lateralen, asymmetrischen und die medianen symmetrischen Formen (Cremer 2005). Das laterale Feuermal hat eine Inzidenz von 0,3 \% (Marler und Mulliken 2005) und erscheint isoliert häufig im Gesichtsbereich als reine kapilläre Gefäßmißbildung. Es kann aber auch kombiniert sein mit Fehlbildungen tieferer Gefäße oder Organen und wird dann als Syndrom, wie zum Beispiel das Hippel-LindauSyndrom, bezeichnet, welches den Phakomatosen zugeordent wird (Siegert et al. 2000). Es imponiert als scharf begrenzter und unregelmäßig konfigurierter, hellroter Fleck, der mit der Zeit lividrot wird (Cremer 2005). Er ist meist einseitig lokalisiert und kann einen Durchmesser von $1 \mathrm{~mm}$ haben oder aber eine ganze Extremität betreffen (Altmeyer und Hoffmann 2005). Mit $83 \%$ tritt das laterale Feuermal meistens im Kopf-/Halsbereich auf (Orten et al. 1996) und zeigt keine spontane Remission. Die Therapie besteht in einer Farbstoff-LaserBehandlung, Argon-Laser Behandlung oder alternativ in der Kryotherapie (Altmeyer und Hoffmann 2005).

Das mediale Feuermal tritt bei Neugeborenen mit einer Inzidenz von 30\% auf (Pratt 1953) und ist eine harmlose, funktionelle Weitstellung der Kapillaren, die meistens im Nackenbereich lokalisiert ist. Es bildet sich meistens spontan zurück (Cremer 2005).

\section{Vorwiegend venöse Malformationen}

Venöse Malformationen werden bei 2-3\% aller Neugeborenen beobachtet (Osburn et al. 1987). Von allen angeborenen vaskulären Malformationen kommen sie mit 50\% am häufigsten vor (Boon et al. 1994). Sie gehören zu den langsam durchflossenen Malformationen (Enjolras 1997). Symptomatisch werden sie meistens erst im jungen Erwachsenenalter, wobei die Klinik ganz von dem Ausmaß der Läsion abhängt. Die Läsionen sehen je nach Tiefe und Ausmaß blau oder violett aus. Sie prägen sich meistens in der Haut und der intestinalen Mukosa aus. In der Histologie weisen diese Venen sich als 
dysplastisch aus und haben Verbindungen zu gesunden Venen. Zudem treten erweiterte Hohlräume auf, die ein irreguläres Lumen besitzen. Die Wanddicke ist vergleichsweise dünn und zeigt eine Reduktion der glatten Muskelzellen in der Tunica media und ein einschichtiges, reif erscheinendes Endothel (Vikkula et al. 1996; Berenguer et al. 1999). Die Mehrzahl der venösen Malformationen tritt sporadisch auf, jedoch hat man bei der Ursachenforschung dieser Erkrankung mehrere Gene entdeckt, die mit verschiedenen Formen dieser Malformationen in Zusammenhang gebracht werden können. Zum einen ist für die multiple kutanomukosale venöse Malformation ein Gendefekt verantwortlich, der auf dem Chromosom 9p lokalisiert ist (Berenguer et al. 1999; Boon et al. 1994; Gallione et al. 1995). Zum anderen hat man bei einer autosomal-dominanten Form der Krankheit eine Mutation im Angiopoetin-Rezeptor-TIE2/TEK-Gen nachweisen können (Vikkula et al. 1996).

Die häufigste Lokalisation venöser Malformationen ist im Kopf- und Halsbereich, sie kann aber auch in jeder anderen Gewebeart vorkommen, wie zum Beispiel intrakraniell oder in inneren Organen (Spring und Bentz 2005). Das Spektrum reicht von einfachen Krampfadern bis hin zu komplexen Läsionen, die mehrere Gewebeschichten betreffen können. Sie bergen die Gefahr der Thrombose und Embolie (van Korlaar et al. 2003). In den meisten Fällen handelt es sich um schwammartige, weiche und kompressible Läsionen, die nicht pulsieren. Je nach Körperlage, wie zum Beispiel beim Valsalva-Manöver, oder bei venöser Kompression vergrößert sich die Läsion (Berenguer et al. 1999). Eine Größenzunahme der Läsionen kann durch Wachstum, hormonelle Störungen und Traumata bedingt sein (Berenguer et al. 1999). Beim Nachweis von Phlebolithen ist die Gefäßmalformation eindeutig den venösen Malformationen zuzuordnen, da sie nur bei diesen vorkommen (Burrows et al. 1998; Yang WT et al. 1997). Des Weiteren werden venöse Malformationen häufig am Morgen durch Missempfindungen symptomatisch, die vermutlich auf 
nächtliche Stase und Mikrothromben zurückzuführen sind. Schon kleinste Läsionen können große Schmerzen verursachen (Berenguer et al. 1999). Venöse Läsionen in den Extremitäten können bei Kindern zu unterschiedlicher Länge der Gliedmaßen führen, je nach Größe der Malformation.

Eine kausale Therapie existiert nicht und bei chirurgischen Interventionen besteht die Gefahr eines induzierten postoperativen Rezidivs des malformierten Gewebes, wobei das Risiko einer Amputation steigt (Ebenebe et al. 2007). Neueste Forschungsergebnisse zeigen Erfolge bei sequenzieller Behandlung mit 595 nm gepulstem Farblaser und 1064 nm Neodym-dotiertem YttriumAluminium-Granat-Laser (Nd:YAG Laser), in denen sich eine vollständige Volumenreduktion des malformierten Gefäßes zeigte (Pereyra-Rodríguez et al. 2009).

\section{Vorwiegend lymphatische Malformationen}

Lymphatische Malformationen entstehen aufgrund einer Anlagestörung im Lymphgefäßssystem in der Embryonalentwicklung und manifestieren sich im Säuglings- oder Kindesalter (Mulliken et al. 2000). Sie sind in der Regel bereits seit der Geburt sichtbar und werden bis zum 2. Lebensjahr symptomatisch (Astner und Anderson 2005). Die lymphatische Malformation kommt mit 75 \% am häufigsten im Kopf- und Halsbereich vor (Ethunandan und Mellor 2006). Die Prävalenz von lymphatischen Malformationen beträgt 1,2 - 2,8 \%o (Filston 1994).

Je nach Lokalisation können Wucherungen im Halsbereich, das Hygroma Colli, zu akuter Atemnot führen und damit lebensbedrohlich sein (Buttler et al. 2009). Lymphatische Malformationen treten als lokalisierte Läsion auf oder sie infiltrieren ganze Körperteile oder Organsysteme. Lymphatische Malformationen in der Darmschleimhaut führen zur 'Protein-LosingEnteropathy' und enden tödlich (Földi et al. 2003). Man unterscheidet 
mikrozystische, makrozystische und gemischte Läsionen (Edwards et al. 2005). Je nach Klinik und Lokalisation entscheidet man sich für eine operative, teilweise komplette Entfernung der Läsion. Die Operation ist bei 15 \% der Fälle mit einer spontanen Regression vergesellschaftet (Buttler et al. 2009).

\section{Arteriovenöse Malformation}

Die arteriovenösen Malformationen gehören $\mathrm{zu}$ den schnell durchflossenen vaskulären Malformationen. Hierbei sind hypertrophe Arterien über einen Nidus direkt mit Venen verbunden, ohne dass ein Kapillarbett dazwischen geschaltet ist (Yakes 2004; Ernemann et al. 2003). In den ersten zwei Lebensdekaden bleiben die Läsionen meistens asymptomatisch (Burrows et al. 1998). Arteriovenöse Malformationen sind am häufigsten intrakraniell und nachfolgend in der Kopf- und Halsregion und den Extremitäten lokalisiert (Marler und Mulliken 2005). Die Symptome sind sehr variabel je nach Lokalisation und Ausprägung. So kann eine arteriovenöse Läsion nie Symptome zeigen oder bei intrazerebralen Läsionen $\mathrm{zu}$ Blutungen führen und lebensbedrohlich werden. Die Symptome reichen von Pulsieren, Schmerzen, Ulzerationen, Gewebeischämie bis zu Blutungen (Kohout et al. 1998). Man nimmt an, dass eine Progredienz der Malformation durch hormonelle Umstellung, wie bei Schwangerschaft und Pubertät, getriggert wird (Fordham et al. 2000). Oft werden diese Läsionen erst nach Traumata oder Infektionen sichtbar (Burrows et al. 1998; Hurwitz und Kerber 1981).

Diagnostisch kann man die Läsionen mittels Farbduplex-Sonographie sichtbar machen oder die Gefäße mittels Angiographie darstellen. Die Therapie ist oft risikoreich und muss je nach Lokalisation sorgfältig abgewogen werden. Eine Embolisation der Läsion ist das Ziel, um das Blutungsrisiko während der chirurgischen Intervention zu senken (Low 2003). 


\section{Arteriovenöse Fisteln}

Arteriovenöse Fisteln bestehen aus einer direkten Verbindung zwischen einer Arterie und Vene und gehören ebenfalls $\mathrm{zu}$ den schnell durchflossenen Malformationen. Sie können kongenital auftreten oder sich erst im Laufe des Lebens entwickeln. Sie können an allen Stellen des Körpers auftreten. Durch den, im Vergleich zur Vene, erhöhten Blutdruck der Arterie, steigt der Blutfluss in dieser Region an. Patienten haben oft ein typisches Pulsieren an der Läsion und man hört mit dem Stethoskop ein Schwirren (Lasjaunias 1997). Die Behandlung besteht zumeist aus einer Embolisation oder einer Stenteinlage.

\subsection{Eigene Fragestellung}

Malformierte Venen sind mit über $50 \%$ die größte Gruppe unter den angeborenen Gefäßmissbildungen (Boon et al. 1994). Die Behandlung der Läsionen macht durch den Einsatz verschiedener, neuer Methoden, wie zum Beispiel durch Laser-Behandlung, weitere Fortschritte, die teilweise schon große Erfolge gezeigt haben (Pereyra-Rodríguez et al. 2009). Einige genetische Dispositionen wurden bei hereditären Formen der Erkrankung, wie oben beschrieben, schon identifiziert. Jedoch sind die wesentlich häufigeren Formen der spontan auftretenden Läsionen und die damit zusammenhängenden Dysregulationen verschiedener Gene noch nicht geklärt. Hier befindet man sich im Anfangsstadium der Erforschung.

Um einen Hinweis auf Gendysregulationen in venösen Malformationen zu erhalten, habe ich die Expression von Molekülen, die typischerweise in Gefäßen vorkommen, immunhistologisch untersucht. Dazu habe ich Antikörper eingesetzt, die im Endothel, in der Tunica media, bei Entzündungen oder der Angiogenese exprimiert werden. Die Moleküle, ihre Lokalisation, Eigenschaften und Funktionen sind im Folgenden aufgelistet (Tabelle 1). Vergleichend habe ich normale Vv. saphenae magnae untersucht, die ich aus Bypass-Operationen 
erhalten habe. Meine Untersuchungen zeigen eine Vielzahl von Unterschieden zwischen gesunden und erkrankten Venen auf.

\begin{tabular}{|c|c|c|c|}
\hline Antikörper gegen & Lokalisation & Eigenschaft & Funktion \\
\hline CD31 (PECAM-1) & $\begin{array}{l}\text { Oberfläche von Blut-, } \\
\text { Lymphendothelzellen } \\
\text { und Leukozyten }\end{array}$ & $\begin{array}{l}\text { Transmembran- } \\
\text { Glykoprotein }\end{array}$ & $\begin{array}{l}\text { Interzelluläre Junktion von } \\
\text { Endothelzellen }\end{array}$ \\
\hline $\begin{array}{l}\text { SMA (Alpha } \\
\text { Smooth Muscle } \\
\text { Actin) }\end{array}$ & $\begin{array}{l}\text { glatte Muskulatur der } \\
\text { Gefäße, Perizyten }\end{array}$ & $\begin{array}{l}\text { Isoform der glatten } \\
\text { Muskelzelle }\end{array}$ & $\begin{array}{l}\text { Stabilität und Kontraktilität } \\
\text { der Gefäße }\end{array}$ \\
\hline CD54 (ICAM-1) & $\begin{array}{l}\text { vaskuläre } \\
\text { Endothelzellen, } \\
\text { Leukozyten }\end{array}$ & $\begin{array}{c}\text { interzelluläres } \\
\text { Adhäsionsmolekül }\end{array}$ & Leukozytenmigration \\
\hline CD62e (ELAM-1) & vaskuläres Endothel & $\begin{array}{l}\text { endotheliales } \\
\text { Zelladhäsionsmolekül } \\
\text { für neutrophile } \\
\text { Granulozyten }\end{array}$ & $\begin{array}{l}\text { Extravasation von } \\
\text { Granulozyten }\end{array}$ \\
\hline CD105 (Endoglin) & $\begin{array}{l}\text { vaskuläres Endothel, } \\
\text { hämatopoetische } \\
\text { Zellen }\end{array}$ & $\begin{array}{l}\text { transmembranes } \\
\text { Glykoprotein }\end{array}$ & $\begin{array}{c}\text { bindet TGFbeta Isoformen } \\
\text { bei Angiogenese, } \\
\text { Wundheilung und } \\
\text { Entzündungen }\end{array}$ \\
\hline $\begin{array}{c}\text { MMP2 (Gelatinase } \\
\text { A) }\end{array}$ & Extrazelluläre Matrix & Enzym, Kollagenase & $\begin{array}{c}\text { Zerlegung der } \\
\text { Extrazellulärmatrix in } \\
\text { Embryonaltentwicklung, } \\
\text { Gewebeneubildung und } \\
\text { Reproduktion }\end{array}$ \\
\hline EphrinB2 & Arterielles Endothel & $\begin{array}{l}\text { Membrangebunder } \\
\text { Ligand für EphB4 }\end{array}$ & $\begin{array}{c}\text { Embryonale Angiogenese, } \\
\text { Anastomosenbildung }\end{array}$ \\
\hline EphB2 & Arterielles Endothel & $\begin{array}{c}\text { Tyrosinkinase-Rezeptor } \\
\text { von EphrinB2 }\end{array}$ & $\begin{array}{c}\text { Ausbildung des vaskulären } \\
\text { Systems, } \\
\text { Nervenausbildung }\end{array}$ \\
\hline EphB4 & Venöses Endothel & $\begin{array}{c}\text { Tyrosinkinase-Rezeptor } \\
\text { von Ephrin B2 }\end{array}$ & $\begin{array}{c}\text { Ausbildung des vaskulären } \\
\text { Systems, } \\
\text { Anastomosenbildung, } \\
\text { Nervenausbildung }\end{array}$ \\
\hline $\begin{array}{c}\text { PAL-E } \\
\text { (Pathologische } \\
\text { Anatomie Leiden- } \\
\text { Endothel } \\
\text { Antikörper) }\end{array}$ & $\begin{array}{l}\text { Endothel von Venen } \\
\text { und kleinen Gefäßen }\end{array}$ & $\begin{array}{c}\text { Plasmalemma vesicle- } \\
\text { associated protein-1 } \\
\text { (PV-1) }\end{array}$ & $\begin{array}{c}\text { Nachweis von venösem } \\
\text { Endothel }\end{array}$ \\
\hline
\end{tabular}

Tabelle 1: Eingesetzte Antikörper: Lokalisation, Eigenschaft und Funktion 


\section{Material und Methoden}

\section{$2.1 \quad$ Geräte}

Zentrifugen:

Mikroskope:

Sonstige:
Kühlzentrifuge Centrifuge 5417R (Eppendorf, Amstetten, Deutschland)

Tischzentrifuge Minizentrifuge Model GMC 060

(LMS Co., LTD, Japan)

Immunfluoreszenzmikroskop (LEICA DM 5000 B,

Bensheim, Deutschland)

Fluoreszenzlampe (Leistungselektronik Jena GmbH, Jena, Deutschland)

Kamera (LEICA Microsystems DI Cambridge (B1),

GB)

Wärmeschrank Memmert (Schütt Labortechnik,

Göttingen, Deutschland)

Kühlschrank Liebherr (Liebherr Hausgeräte,

Ochsenhausen, Deutschland)

Gefrierschrank Liebherr (Liebherr Hausgeräte,

Ochsenhausen, Deutschland)

Kryotom (LEICA CM 30505, Bensheim, Deutschland)

Physio Care Pipetten (Eppendorf, Hamburg,

Deutschland)

Präparationsbesteck (Aesculap, Tuttlingen,

Deutschland)

Feuchte Kammer 


\subsection{Verbrauchsmaterialien}

Deckgläser 20 x 60mm

Einmalhandschuhe

Pipettenspitzen

Reaktionsgefäße mit Deckel

Superfrost-Objektträger
(Menzel-Gläser, Rettberg, Göttingen,

Deutschland)

(Hartmann, Heidenheim, Deutschland)

(Eppendorf, Hamburg, Deutschland)

(Eppendorf, Hamburg, Deutschland)

(Menzel-Gläser, Braunschweig, Deutschland)

\subsection{Chemikalien}

Aqua dest.

Dikaliumhydrogenphosphat

Dinatriumhydrogenphosphat

Fluoromount-G

Kaliumdihydrogenphosphat

Kaliumhydrogenphosphat

Leitungswasser

Natriumchlorid

Tissue Tek
(Seradest; Veolia Water Solutions)

(Merck, Darmstadt, Deutschland)

(Merck, Darmstadt, Deutschland)

(Southern Biotechnology Associates,

Birmingham, USA)

(Merck, Darmstadt, Deutschland)

(Merck, Darmstadt, Deutschland)

(Roth, Karlsruhe, Deutschland)

Einbettmedium für Gefrierschnitte (Sakura

Finetek Europe B.V., Niederlande)

\subsection{Histologie}

\section{Gewebeproben}

Die von mir untersuchten venösen Malformationen haben wir von Patienten erhalten, die für eine Operation vorgesehen waren. Die malformierten Venen wurden vorab mittels Doppler Sonografie und weiteren radiologischen Verfahren diagnostiziert. Diese Venen wurden an den Beinen von erkrankten Patienten im Alter von 16 bis 36 Jahren $(n=8)$ reseziert. Die klinische Diagnose wurde von einem erfahrenem Pathologen bestätigt. Die Präparate wurden von 
Herrn Prof. Dr. med. D. A. Loose (Abteilung für Angiologie und Gefäßchirurgie der Chirurgischen Klinik Dr. Guth, Hamburg) zur Verfügung gestellt. In der folgenden Abbildung 1 wird ein Beispiel eines von Prof. Dr. D. A. Loose behandelten Patienten mit malformierten Venen in der linken Extremität gezeigt:

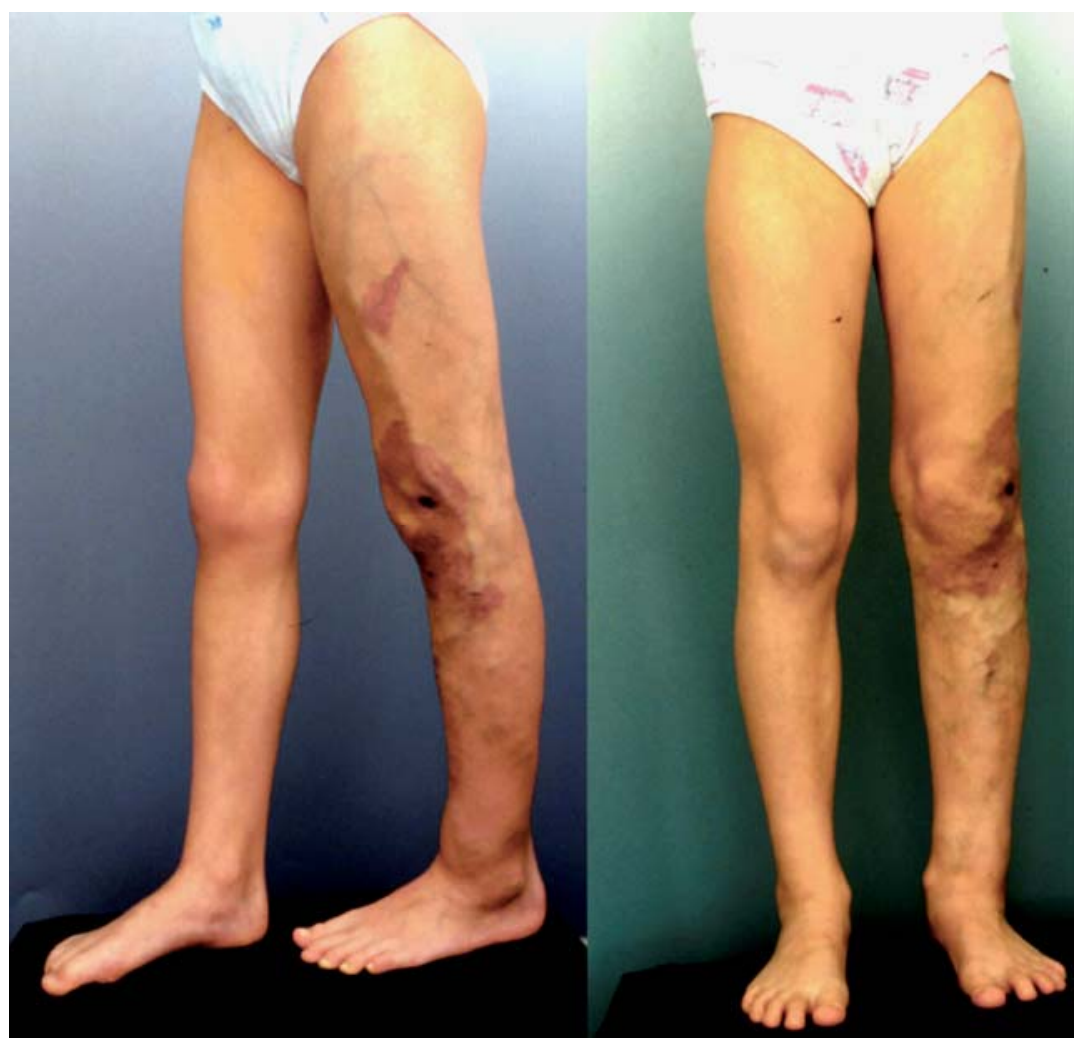

Abbildung 1: Patient mit malformierten Venen in der unteren Extremität (Quelle: Prof. Dr. D. A. Loose, Hamburg)

Das Kontrollgewebe wurde in aortokoronaren Venenbypass-Operationen am Universitätsklinikum Göttingen an Patienten im Alter zwischen 46 und 73 Jahren $(n=4)$ gewonnen. Die 1 bis $2 \mathrm{~cm}$ langen Gewebeproben der Vena saphena magna wurden in 0,5 cm lange Gewebeproben mit Präparationsbesteck geteilt und direkt mit 0,1 M phosphatgepufferter Kochsalzlösung (PBS) gespült.

Die venösen Malformationen und das Kontrollgewebe wurden in flüssigem Stickstoff schockgefroren, um dann im Gefrierschrank bei $-80{ }^{\circ} \mathrm{C}$ gelagert zu werden. 
Untersuchungen der Gewebe fanden mit Zustimmung der Patienten und des Ethik-Komitees der UMG statt (Nr.: 6/1/04).

\section{Herstellung von Kryoblöcken}

Die in meiner Untersuchung verwendeten Venen wurden im Kryostat bei $-20^{\circ} \mathrm{C}$ in einem Kryomedium (Tissue Tek) eingebettet und bei dieser Temperarur ausgehärtet. Anschließend wurden die Kryoblöcke in Aluminiumfolie verpackt und nummeriert im Gefrierschrank bei $-80^{\circ} \mathrm{C}$ gelagert oder direkt $\mathrm{zu}$ Gefrierschnitten verarbeitet und auf Objektträger aufgebracht.

\section{Herstellung von Gefrierschnitten}

Bei einer Kammertemperatur von $-20^{\circ} \mathrm{C}$ wurden die Gewebsschnitte mit einer Dicke von $16 \mu \mathrm{m}$ im Kyromikrotom angefertigt und auf Superfrost-Objektträger transferiert. Die Gewebsschnitte wurden für mindestens $1 \mathrm{~h}$ bei Raumtemperatur getrocknet; bei direkter Weiterverarbeitung für Immunfluoreszenzfärbungen. Anderenfalls wurden sie bei $-20^{\circ} \mathrm{C}$ in Einfrierboxen gelagert. 


\subsection{Immunfluoreszenz}

Standardlösungen für die Immunhistologie

BSA: $\quad$ 1\% Rinderserumalbumin

KPP: $\quad$ 0,1 M Kalium-Phosphatpuffer:

1,088g Kaliumdihydrogenphosphat

13,92g Dikaliumhydrogenphosphat

ad $440 \mathrm{ml}$ Aqua dest., anschließend Verdünnung 1:1 mit

Aqua dest.; $\mathrm{pH} 7,4-7,8$

PBS: $\quad$ 0,1 M Phosphatgepufferte Kochsalzlösung

72,0 g Natriumchlorid

14,8g Dinatriumhydrogenphosphat

4,3 g Kaliumhydrogenphosphat

ad 1000 ml Aqua dest.; pH 7,2

Eindeckmedium: Fluoromount-G (Southern Biotechnology Associates, Birmingham, GB)

\section{Antikörper für die Immunfluoreszenz}

Die folgende Auflistung zeigt, welche primären und sekundären Antikörper in meinen Untersuchungen verwendet wurden. Die jeweilig angegebenen Verdünnungen der Antikörper wurden mit 0,1 M KPP-Lösung im Reaktionsgefäß hergestellt. 


\section{Primärantikörper:}

CD31

mouse-anti-human CD31 (1:50; Research Diagnostics, Flanders NJ, USA)

SMA

mouse-anti-human $\alpha$-SMA (1:2000; Sigma Aldrich,

Deisenhofen, Deutschland)

CD54

mouse-anti-human CD54 (1:1000; Serotec, Oxford, UK)

CD62e

mouse-anti-human CD62e (1:100; Serotec, Oxford, UK)

CD105

mouse-anti-human CD105 (1:100; Serotec, Oxford, UK)

EphB2

rabbit-anti-mouse EphB2 (1:400; zur Verfügung gestellt

von Prof. Dr. R. Klein, MPI, Martinsried)

EphB4

rabbit-anti-mouse EphB4 (1:1000; zur Verfügung gestellt

von Prof. Dr. R. Klein, MPI, Martinsried)

EphrinB2

goat-anti-mouse EphrinB2 (1:50; R\&D Systems, Abingdon, $\mathrm{UK})$

PAL-E

mouse-anti-human PAL-E (1:200; Research Diagnostics, Flanders NJ, USA)

MMP2

mouse-anti-human MMP2 (1:1000; Chemicon

International, Chandlers Ford, UK)

\section{Sekundärantikörper:}

Alexa Fluor 488 goat-anti-mouse IgG (1:200; Molecular Probes, Leiden, Niederlande)

Alexa Fluor 488 donkey-anti-rabbit IgG (1:200; Molecular Probes, Leiden, Niederlande)

Alexa Fluor 488 donkey-anti-goat IgG (1:200; Molecular Probes, Leiden, Niederlande)

Alexa Fluor 594 goat-anti-mouse IgG (1:200; Molecular Probes, Leiden, Niederlande)

Alexa Fluor 594 sheep-anti-mouse IgG (1:200; Molecular Probes, Leiden, Niederlande) 


\section{Immunfluoreszenz-Färbung}

Unspezifische Bindungen, zum Beispiel an Kollagen, wurden zunächst mit je $600 \mu \mathrm{l}$ \%igem BSA (bovine serum albumin) für $1 \mathrm{~h}$ bei Raumtemperatur in einer Feuchtkammer geblockt. Dann wurde der Primärantikörper in der oben genannten Konzentration auf die Gewebeschnitte aufgetragen und das Präparat für $1 \mathrm{~h}$ in der Feuchtkammer inkubiert. Vor der Verdünnung wurden die sekundären Antikörper für $5 \mathrm{~min}$ bei 10000 Umdrehungen zentrifugiert (Kühlzentrifuge Centrifuge 5417R), um zu verhindern, dass Fluoreszenzkristalle in die Lösung kommen. Nach einem kurzen Waschschritt mit 2 × $600 \mu 1$ 0,1 M KPP erfolgte die Inkubation mit dem Sekundärantikörper für $1 \mathrm{~h}$ bei Raumtemperatur in der Feuchtkammer. Nach diesem Inkubationsschritt wurden die Schnitte mit $4 \times 600 \mu 1$ 0,1 M KPP gewaschen und mit FluoromountG eingedeckelt. Die Präparate wurden über Nacht lichtgeschützt getrocknet und anschließend bei $4{ }^{\circ} \mathrm{C}$ lichtgeschützt gelagert. Die Analyse der Präparate erfolgte mit dem Mikroskop LEICA DM 5000 B durch Anregung der Farbstoffe mit Licht geeigneter Wellenlänge. 


\section{Ergebnisse}

\subsection{Immunfluoreszenz-Einzelfärbungen}

Es wurden zunächst Einzelfärbungen mit den Antikörpern gegen CD31 und SMA durchgeführt, um eine Übersicht über die Morphologie der Venen zu erhalten. Zudem habe ich die Antikörper CD54, CD62e, CD105 und MMP2 vewendet, um eventuelle Entzündungszeichen und Umbauvorgänge nachzuweisen. Bei den Einzelfärbungen habe ich auch die Verteilung von Elastin untersucht. Elastin besitzt unter UV-Anregung eine hohe Autofluoreszenz. Elastin stellt sich in den Abbildungen blau und die mit Antikörper untersuchten Genexpressionen grün dar. Somit unterscheidet sich das Elastin-Signal vom spezifischen Signal.

\section{CD31 (PECAM-1)}

Das Molekül CD31 (PECAM-1) ist ein $130 \mathrm{kDa}$ schweres TransmembranGlykoprotein der Immunoglobulin Superfamilie und wird auf der Oberfläche von Blut- und Lymphendothelzellen, sowie einigen Leukozyten exprimiert. CD31 ist auch Bestandteil der interzellulären Junktion von Endothelzellen (van Mourik et al. 1985; Muller et al. 1989; Albelda et al. 1990). Aufgrund seiner konstanten Expression im Endothel wird es als Marker für diese Zellen verwendet. 

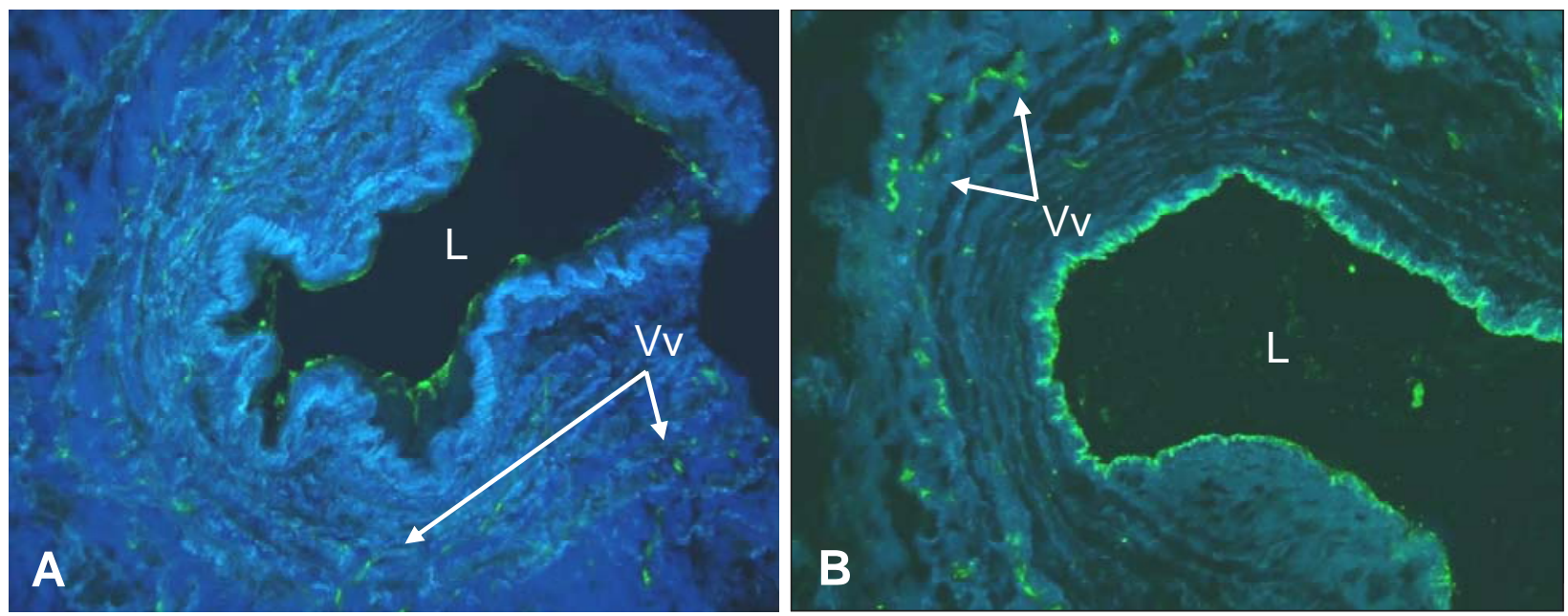

Abbildung 2: Einzelfärbungen mit Antikörpern gegen CD31 an normalen Venae saphenae magnae

A, B) Das Endothel der Vene und der Vasa vasorum (Vv) sind CD31-positiv. Elastin stellt sich blau dar, während sich der Endothelmarker CD31 grün darstellt. Lumen der Vene (L). ObjektivVergrößerung 10x. 

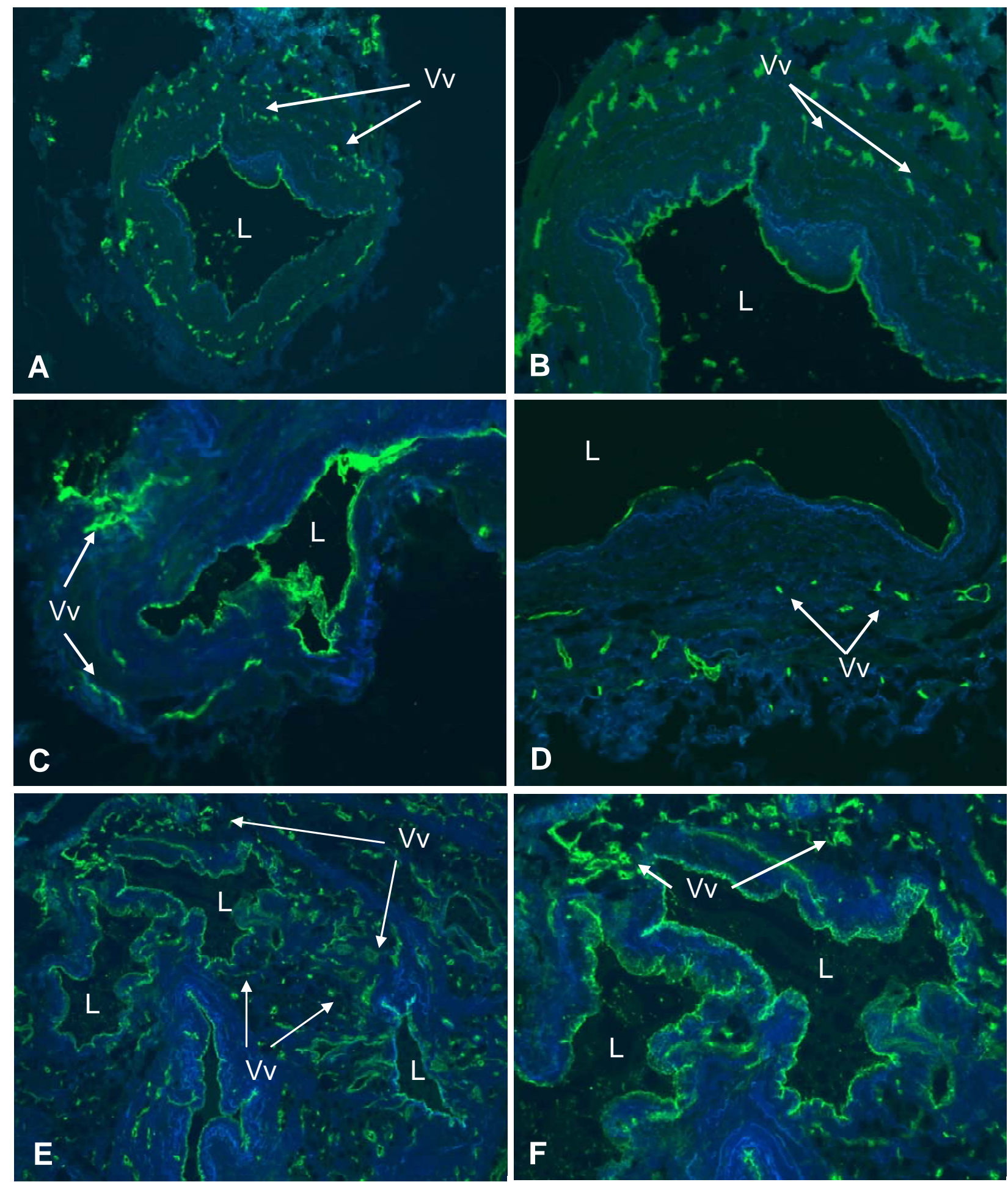

Abbildung 3: Einzelfärbung mit Antikörpern gegen CD31 an malformierten Venen

A-F) Die Endothelzellen der Venen und der Vasa vasorum ( $\mathrm{Vv}$ ) exprimieren CD31. Lumen der Venen (L). Die Vasa vasorum reichen teilweise bis in die Tunica media oder bis zur Intima. Die Venen weisen viele Aussackungen auf. Elastin stellt sich blau dar, während sich der Endothelmarker CD31 grün darstellt.

B, C, D,F) Objektiv-Vergrößerung 10x. A, E) Objektiv-Vergrößerung 5x.

In den normalen und malformierten Venen kann man erkennen, dass die Endothelzellen der großlumigen Venen und der Vasa vasorum CD31 
exprimieren (Abb. 2). Die Vasa vasorum der normalen Venen befinden sich hauptsächlich in der Adventitia. Bei den malformierten Venen kann man beobachten, dass die Vasa vasorum bis tief in die Media reichen und teilweise auch in der Nähe des Venenendothels liegen. Das Lumen der Venen ist sehr unregelmäßig geformt und weist viele Aussackungen auf (Abb. 3).

\section{Alpha Smooth Muscle Actin (SMA)}

Alpha Smooth Muscle Actin (SMA) ist eine Isoform des Aktins der glatten Muskelzellen. SMA befindet sich vor allem in der glatten Muskulatur der Gefäße in gebündelter Form sowie in Perizyten und Myofibroblasten (Skalli et al. 1989). Die Tunica media besteht aus elastischen und vielen kollagenen Fasern sowie glatten Muskelzellen. Die Media ist in Venen im Vergleich zu Arterien mit gleichem Durchmesser deutlich dünner ausgeprägt und besitzt wesentlich weniger glatte Muskelzellen und mehr Bindegewebe.
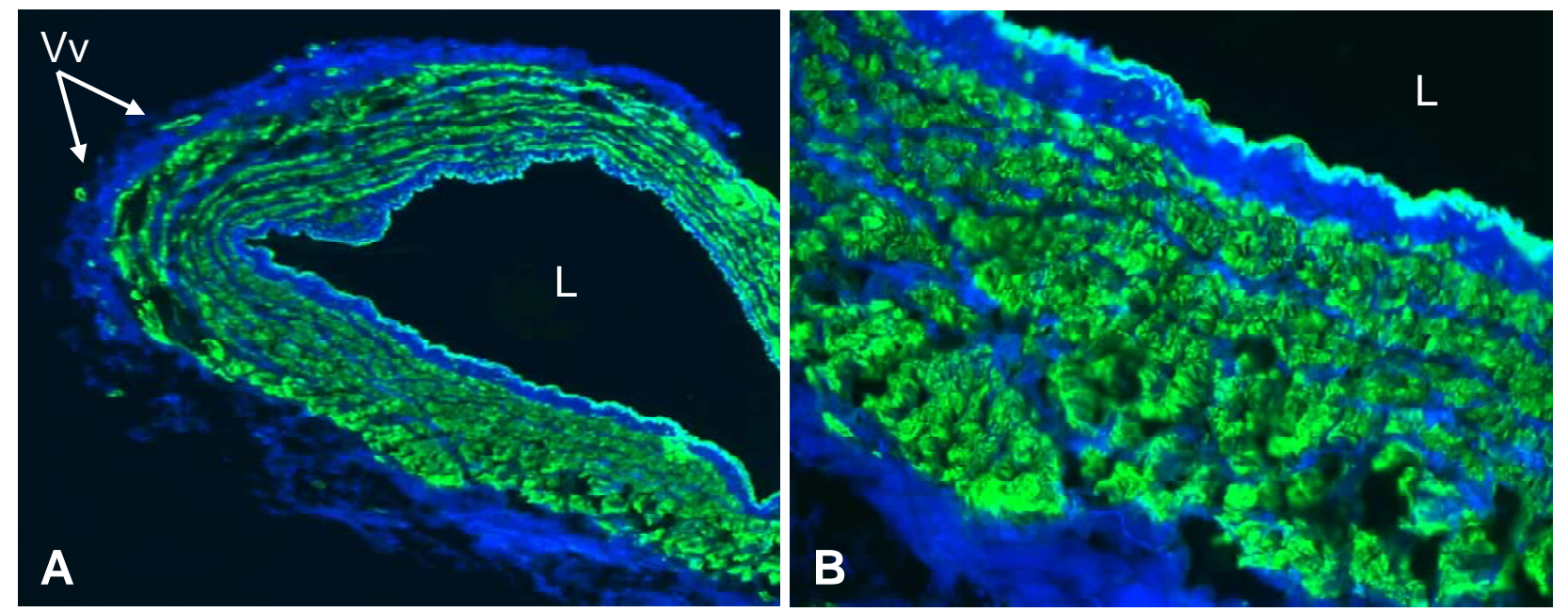

Abbildung 4: Einzelfärbung mit Antikörpern gegen SMA an einer normalen Vena saphena magna

A) Die immunhistologische Anfärbung zeigt SMA-Signale (grün) in der Tunica media des Gefäßes. Lumen der Vene (L). Vasa vasorum (Vv). Objektiv-Vergrößerung 5x. B) Hier zeigt sich an derselben Vene die geordnete Struktur der Muskelfasern (grün) in stärkerer Vergrößerung. Auch in der Intima sind SMA-positive Zellen zu sehen. Lumen der Vene (L). ObjektivVergrößerung 20x. 

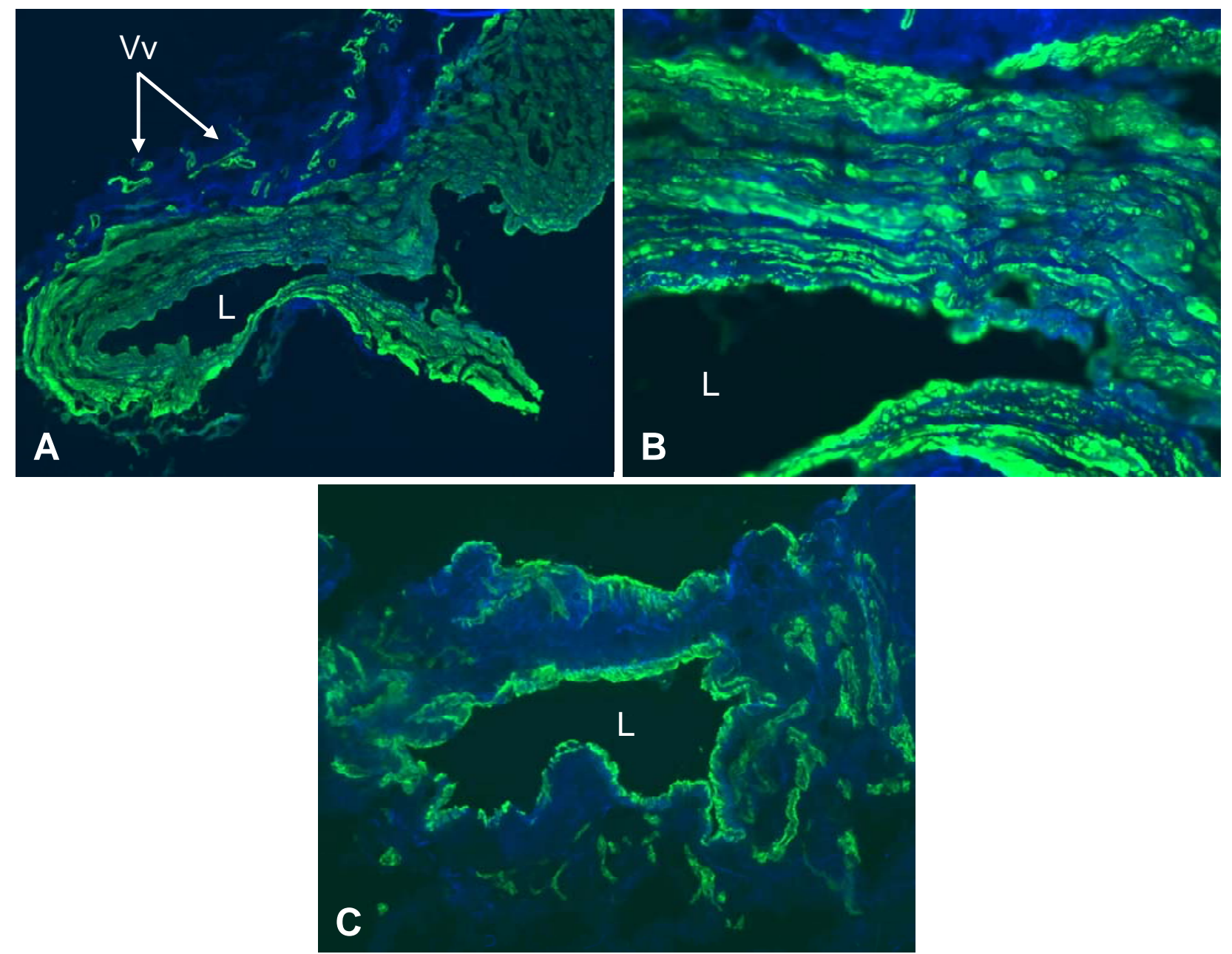

Abbildung 5: Einzelfärbung mit Antikörpern gegen SMA an malformierten Venen

A) Die Muskelfasern des Gefäßes stellen sich SMA-positiv (grün) dar. Man erkennt eine aufgelockerte Muskelfaseranordung in der Tunica media und erhebliche Differenzen in der Wanddicke. Lumen der Vene (L); Vasa vasorum (Vv). Objektiv-Vergrößerung 5x. Aus: Ebenebe et al. 2007, S. 766. B) Hier wird dasselbe Gefäß wie in A) dargestellt in stärkerer Vergrößerung. Man kann sehen, dass die Muskelbündel (grün) einen weniger geordneten Verlauf besitzen. Lumen der Vene (L). Objektiv-Vergrößerung 20x. C) Eine andere malformierte Vene, deren Tunica media deutlich vermindert erscheint. Es zeigen sich wenige SMA-positive Zellen (grün). Lumen der Vene (L). Objektiv-Vergrößerung 10x.

Man kann beobachten, dass SMA bei den normalen und malformierten Venen in der Tunica media von den glatten Muskelzellen und in der Media der Vasa Vasorum exprimiert wird. Die Anordnung der Muskelfasern in den normalen Venen ist gerichtet und geordnet (Abb. 4). Die malformierten Venen scheinen eine unregelmäßigere Muskelfaserbündelung in der Tunica media zu besitzen (Abb. 5). Außerdem ist die Dicke der Wandschicht sehr unregelmäßig. In Abbildung 5 A kann man dies besonders gut sehen: Zum einen weist die malformierte Vene eine sehr dünne, filiforme Wanddicke auf und zum anderen 
deutlich verdickte Wandanteile. Es zeigen sich somit proliferative Anteile der Muskelschichten neben degenerativen Veränderungen.

\section{CD54 (ICAM-1)}

CD54 (ICAM-1) ist ein interzelluläres Adhäsionsmolekül mit einem Gewicht von 85-110 kDa und gehört zur Ig Superfamilie. Es wird auf vaskulären Endothelzellen und Leukozyten exprimiert. ICAM-1 ist ein Ligand für den Rezeptor LFA-1 (Rothlein et al. 1986). Über diesen Liganden-Rezeptor Komplex können Leukozyten in das Gewebe einwandern (Yang L et al. 2005).
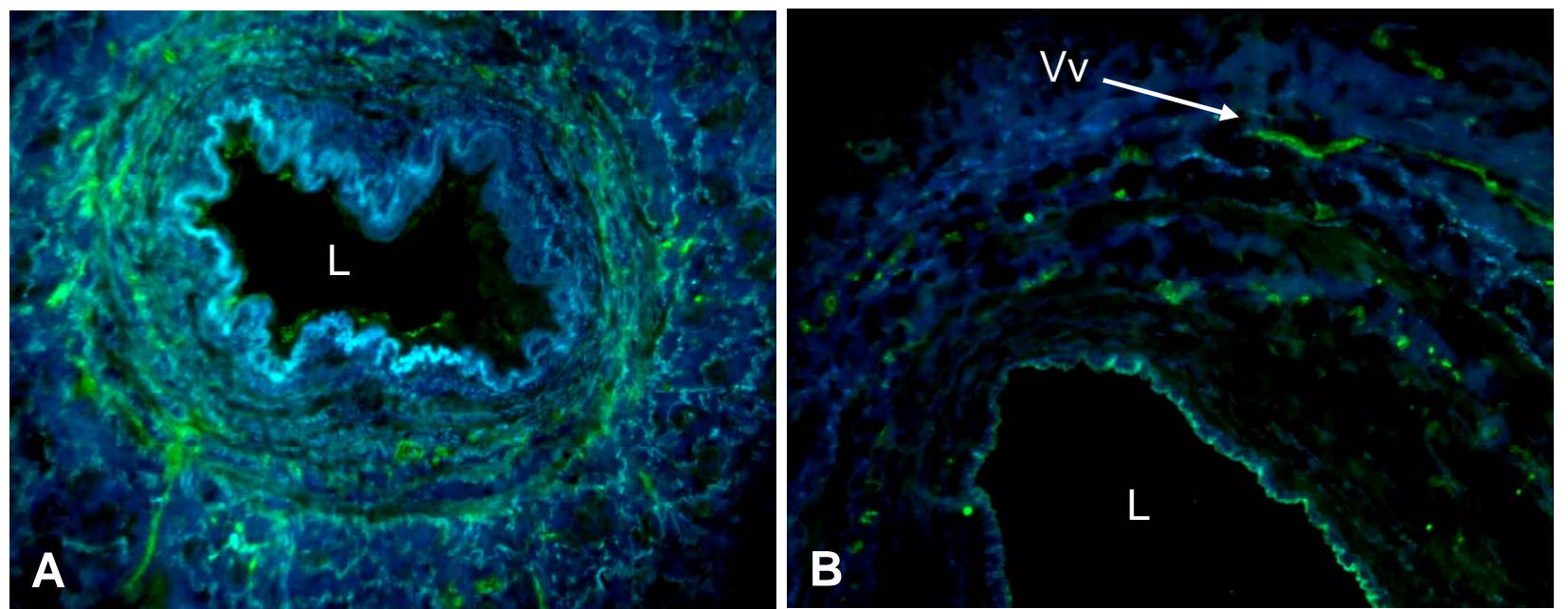

Abbildung 6: Einzelfärbung mit Antikörpern gegen CD54 an normalen Venae saphenae magnae

A) CD54 (grün) wird an wenigen Endothelzellen der Vene exprimiert. Lumen der Vene (L). Objektiv-Vergrößerung 10x. Aus: Ebenebe et al. 2007, S. 769. B) Die Endothelzellen der Vene und die der Vasa vasorum (Vv) sind hier teilweise CD54-positiv (grün). Lumen der Vene (L). Objektiv-Vergrößerung 10x. 

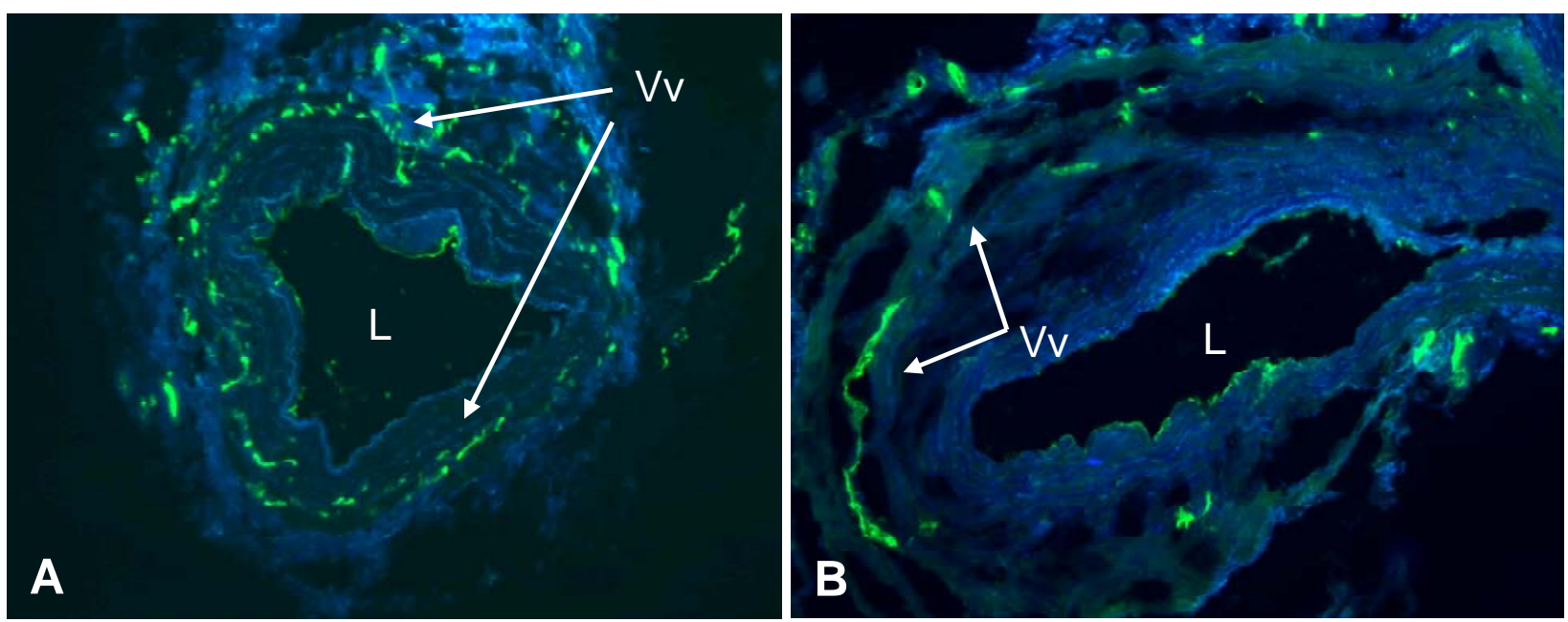

Abbildung 7: Einzelfärbung mit Antikörpern gegen CD54 an malformierten Venen

A) An dieser malformierten Vene kann man deutlich erkennen, wie stark und wie zahlreich die Endothelzellen der Vasa vasorum (Vv) CD54 (grün) exprimieren. Sie befinden sich in der gesamten Adventitia und teilweise in der Tunica media. Lumen der Vene (L). ObjektivVergrößerung 5x. Aus: Ebenebe et al. 2007, S. 769. B) Das Endothel der Vasa vasorum (Vv) dieser Vene ist ebenfalls deutlich CD54-positiv (grün). Lumen der Vene (L). ObjektivVergrößerung 10x.

Bei den untersuchten normalen Venen kann man erkennen, dass CD54 von wenigen Endothelzellen gebildet wird (Abb. 6). Hingegen sieht man bei den Vasa vasorum der malformierten Venen eine deutlich erhöhte Expression, was auf ein Entzündungsgeschehen in der Tunica media und Tunica adventitia deutet (Abb. 7) .

\section{CD62e (ELAM-1)}

CD62e (ELAM-1) ist ein 115kDa großes endotheliales Zelladhäsionsmolekül für neutrophile Granulozyten und spielt eine Schlüsselrolle bei der Extravasation von Entzündungszellen in das umliegende Gewebe (Picker et al. 1991). 


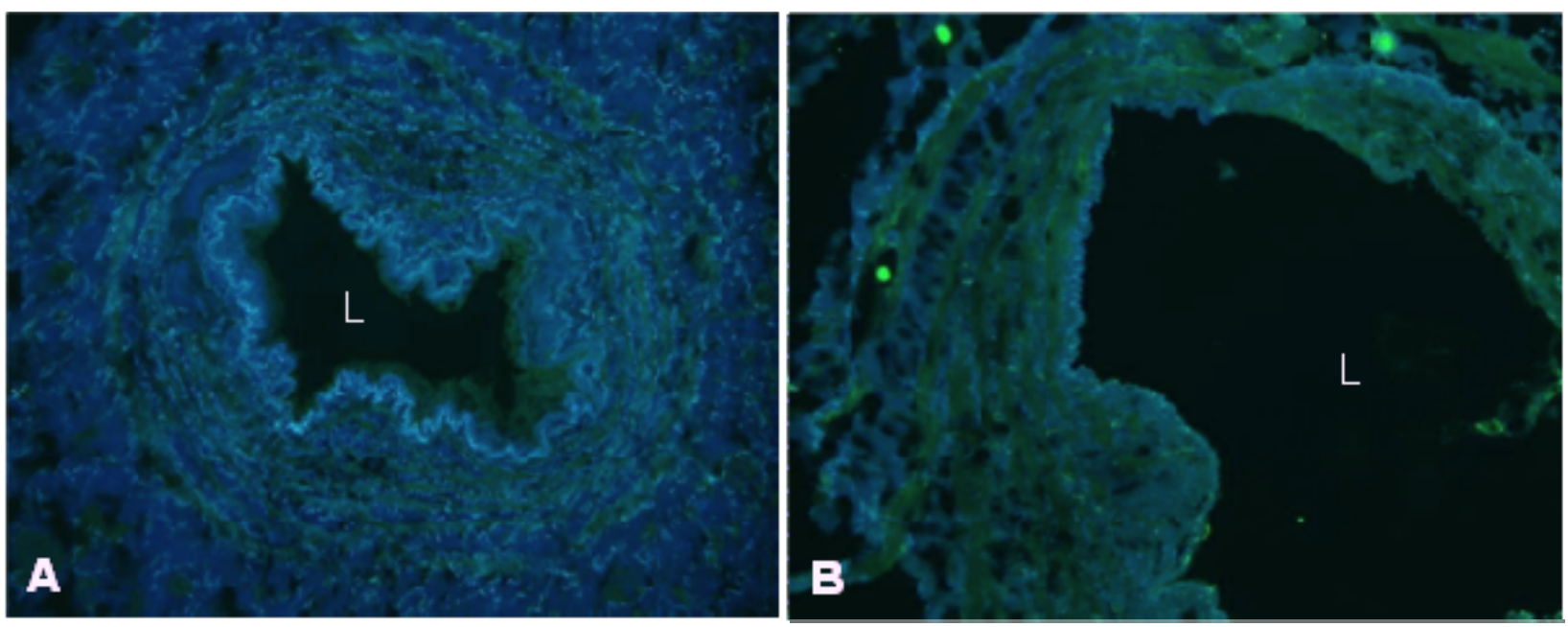

Abbildung 8: Einzelfärbung mit Antikörpern gegen CD62e an normalen Venae saphenae magnae

A) Diese Vene zeigt bei ihrer Untersuchung sehr wenig bis gar keine Expression von CD62e (grün). Lumen der Vene (L). Objektiv-Vergrößerung 10x. Aus: Ebenebe et al. 2007, S. 769. B) Die Endothelzellen dieses Gefäßes und ihrer Vasa vasorum lassen ebenfalls auf wenig bis gar keine Synthese von CD62e (grün) schließen. Lumen der Vene (L). Objektiv-Vergrößerung 10x.

Ich konnte beobachten, dass das Endothel von normalen Venen und ihrer Vasa vasorum sehr wenig bis gar kein CD62e exprimieren (Abb. 8). Die Vasa vasorum der untersuchten malformierten Venen hingegen weisen in den meisten Fällen eine Vielzahl von Vasa vasorum auf, die CD62e exprimieren (Abb. 9). Dies deutet ebenfalls auf ein Entzündungsgeschehen im Bereich der Vasa vasorum hin. 

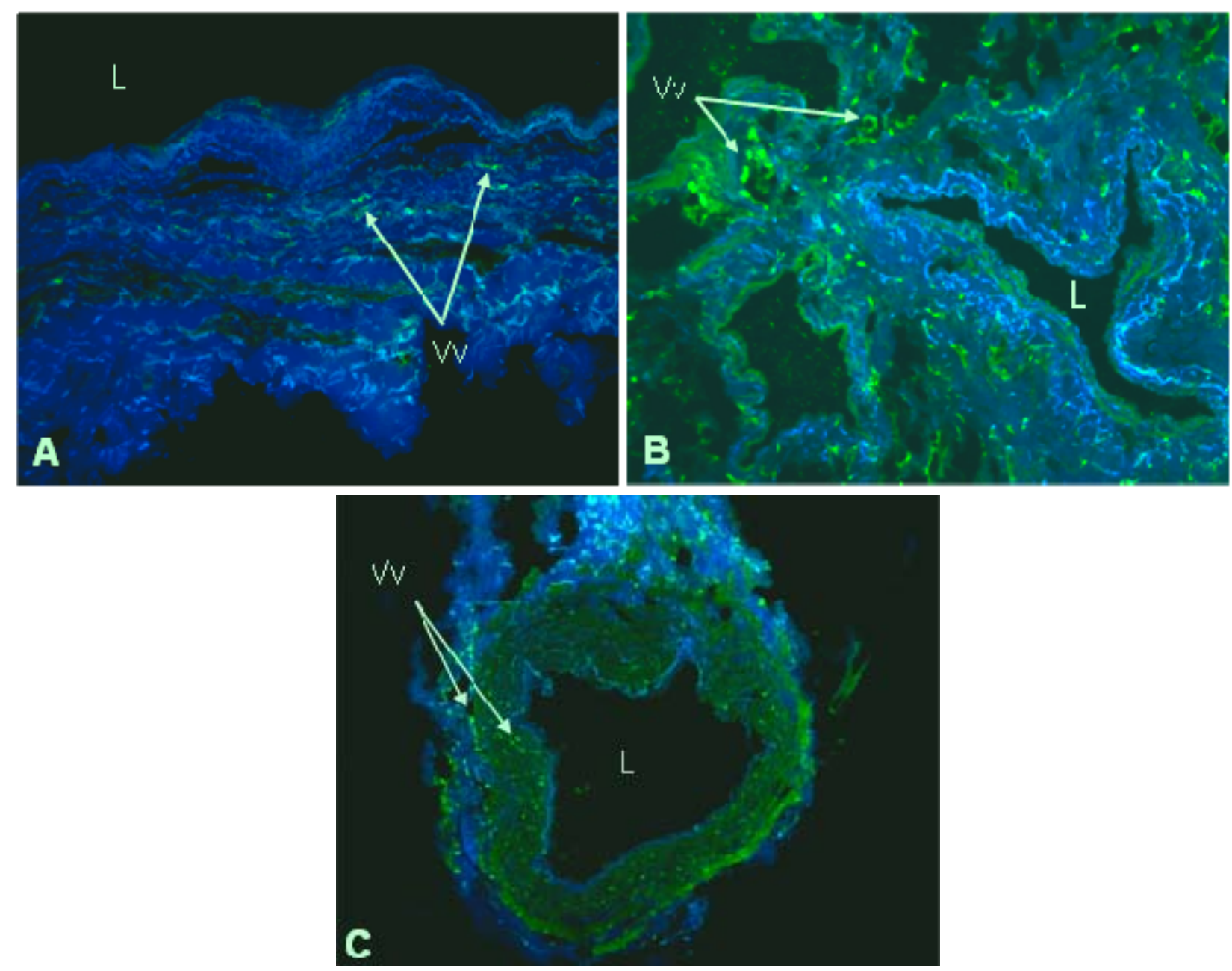

Abbildung 9: Einzelfärbung mit Antikörpern gegen CD62e an malformierten Venen

A) Das Endothel dieser malformierten Vene ist nicht CD62e-positiv, jedoch einige Vasa vasorum (Vv) (grün). Lumen der Vene (L). Objektiv-Vergrößerung 10x. B) In dieser malformierten Vene zeigen sich wesentlich mehr CD62e-positive (grün) Vasa vasorum (Vv) als in Vene (A). Lumen der Vene (L). Objektiv-Vergrößerung 5x. Modifiziert aus: Ebenebe et al. 2007, S. 769. C) Die Übersicht dieser Vene zeigt die vermehrte Expression von CD62e anhand der Anzahl positiver Vasa vasorum (Vv). Lumen der Vene (L). Objektiv-Vergrößerung 5x.

\section{CD105 (Endoglin)}

CD105 (Endoglin) ist ein $180 \mathrm{kDa}$ schweres transmembranes Glykoprotein. Es wird auf vaskulärem Endothel und hämatopoetischen Zellen exprimiert und bindet TGFbeta Isoformen. Seine Expression wird während der Angiogenese, der Wundheilung und der Entzündungen hoch reguliert (Arthur et al. 2000). 

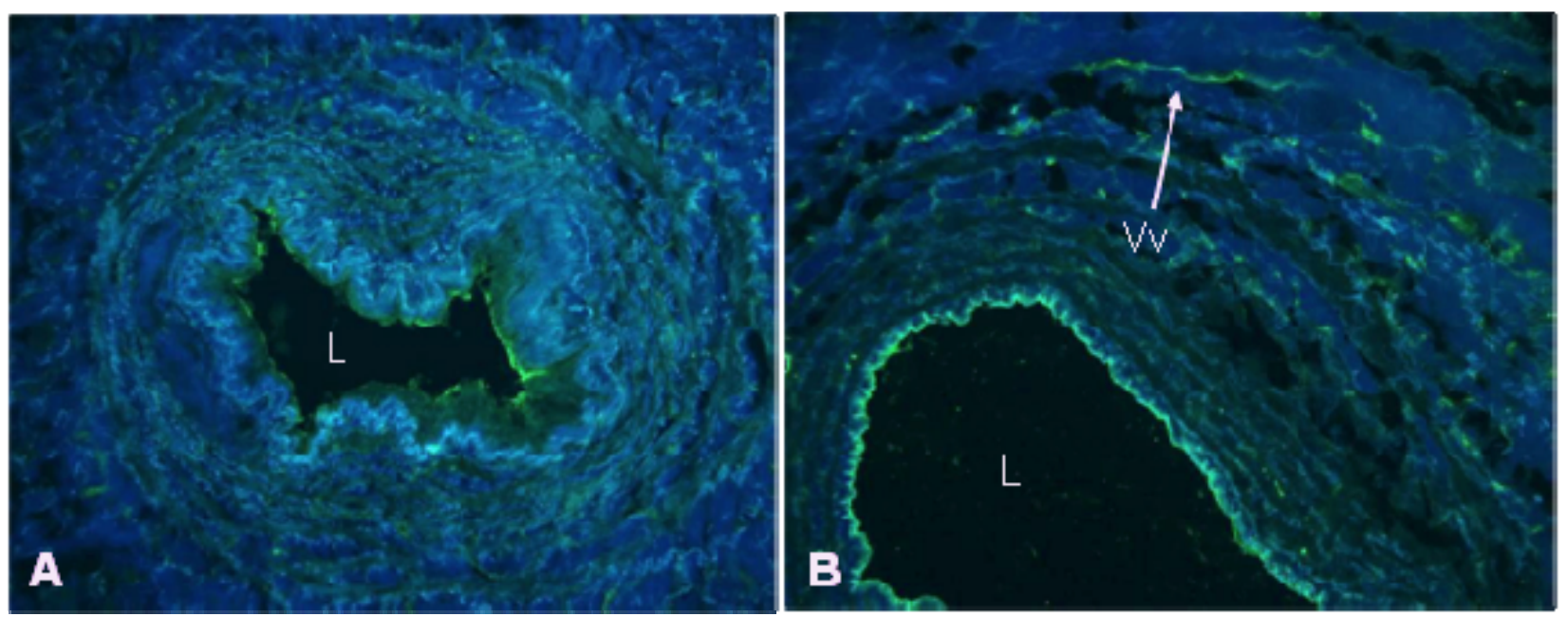

Abbildung 10: Einzelfärbung mit Antikörpern gegen CD105 an normalen Venae saphenae magnae

A) Das Endothel der Vene zeigt eine starke Expression von CD105 (grün). Lumen der Vene (L). Objektiv-Vergrößerung 10x. B) In diesem Präparat kann man die Expression von CD105 (grün) im Endothel der Vene und ihrer Vasa vasorum (Vv) beobachten. Lumen der Vene (L). ObjektivVergrößerung 10x. 

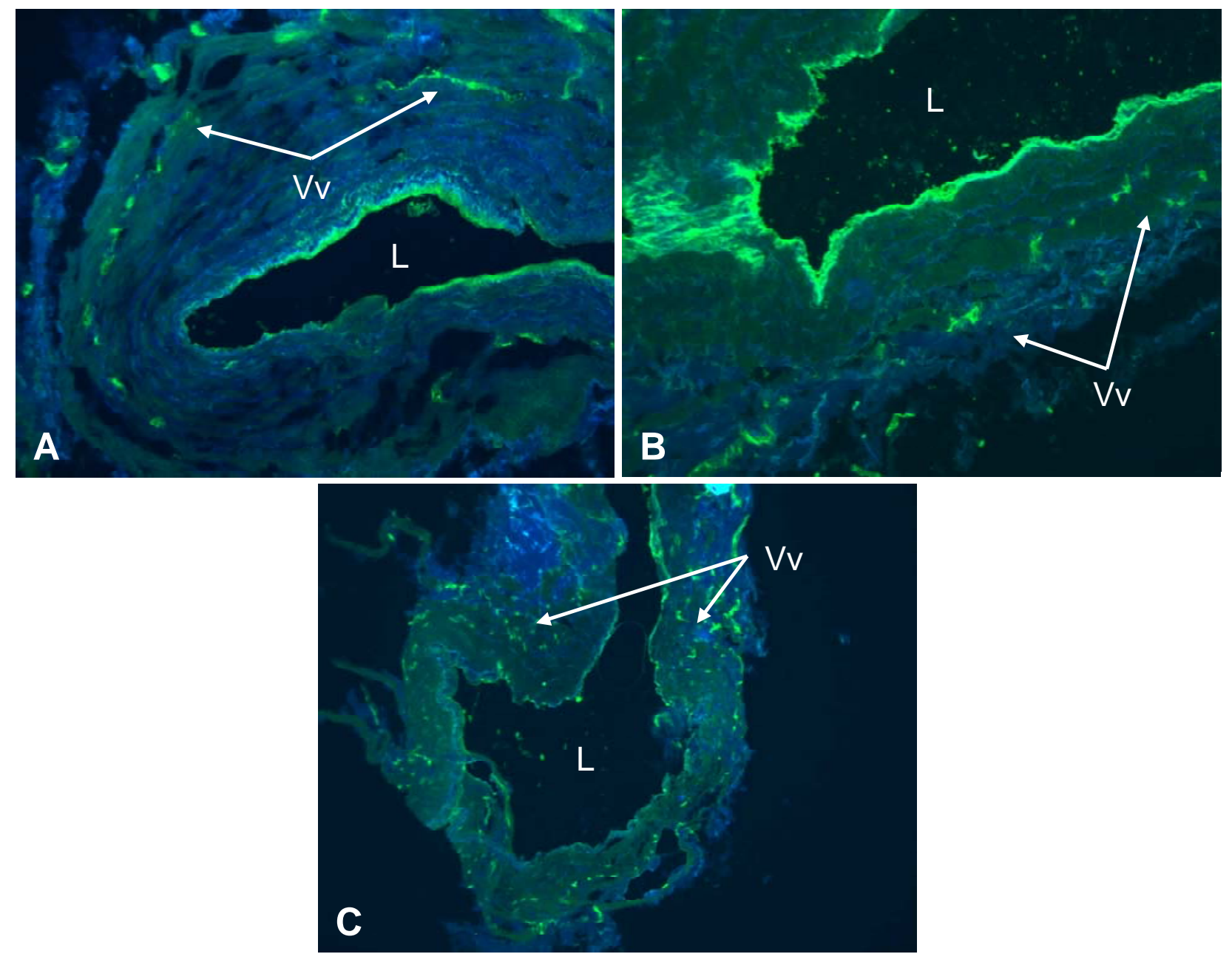

Abbildung 11: Einzelfärbung mit Antikörpern gegen CD105 an malformierten Venen

A) Endothel der Vene und der Vasa vasorum (Vv) zeigen deutliche Expression von CD105 (grün). Die Vasa vasorum befinden sich hier in der Adventitia. Lumen der Vene (L). ObjektivVergrößerung 10x. B) Hier erscheinen die Vasa vasorum (Vv) und das Endothel stark CD105positiv (grün) und die Vasa vasorum reichen von der Adventitia bis in die Media hinein. Lumen der Vene (L). Objektiv-Vergrößerung 10x. C) In der Übersicht dieser Vene sieht man eine eindeutige Signalanhebung im Bereich der Vasa vasorum $(\mathrm{Vv})$, welche ebenfalls in der Adventitia und Media lokalisiert sind. Lumen der Vene (L). Objektiv-Vergrößerung 5x.

Das Endothel der normalen und malformierten Venen hat in den Untersuchungen CD105 exprimiert (Abb. 10, 11). Auch hier zeigten die Vasa vasorum der malformierten Venen eine deutlich erhöhte Synthese dieses Markers. Dies unterstützt die Annahme, dass es sich um Entzündungen im Bereich der Vasa vasorum der malformierten Venen handelt. Man kann ebenfalls beobachten, dass die Anzahl der das Gefäß versorgenden Gefäße bei den malformierten Venen erhöht ist. Die Vasa vasorum der malformierten Venen aus der Abbildung 11 B) und C) weisen Vasa vasorum in der Adventitia und bis tief in der Media auf. 


\section{MMP2 (Gelatinase A)}

MMP2 (Gelatinase A), das zu der Familie der Matrix-Metalloproteinasen gehört, ist ein $72 \mathrm{kDa}$ schweres Enzym, das an der Degradation der Extrazellulär-Matrix bei physiologischen und pathologischen Prozessen beteiligt ist. Dazu zählen die Embryonalentwicklung, Reproduktion und Gewebeneubildungen wie zum Beispiel die Angiogenese und Entstehung von Granulationsgewebe bei Entzündungen (Zigrino et al. 2001; Nagase et al. 1992).
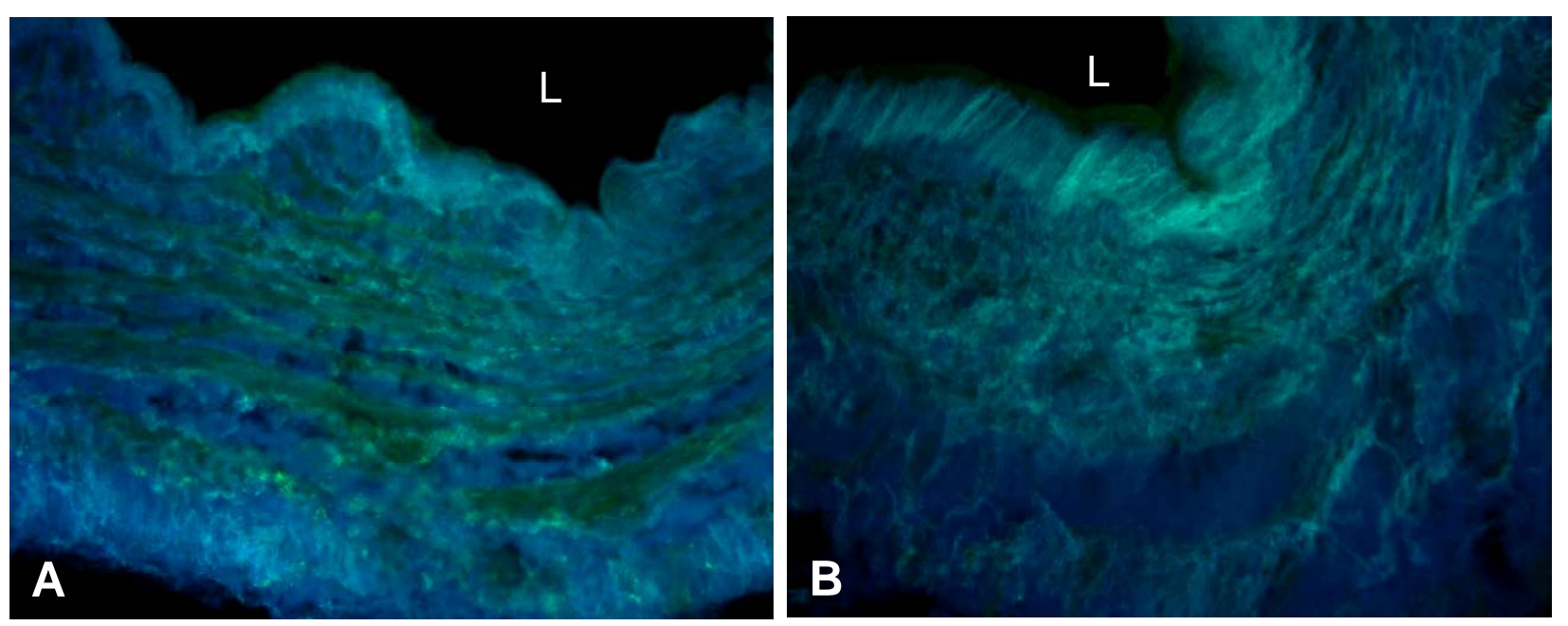

Abbildung 12: Einzelfärbung mit Antikörpern gegen MMP2 an normalen Venae saphenae magnae

A, B) In beiden normalen Venen kann keine Expression von MMP2 (grün) festgestellt werden. Lumen der Vene (L). Objektiv-Vergrößerung 10x. 

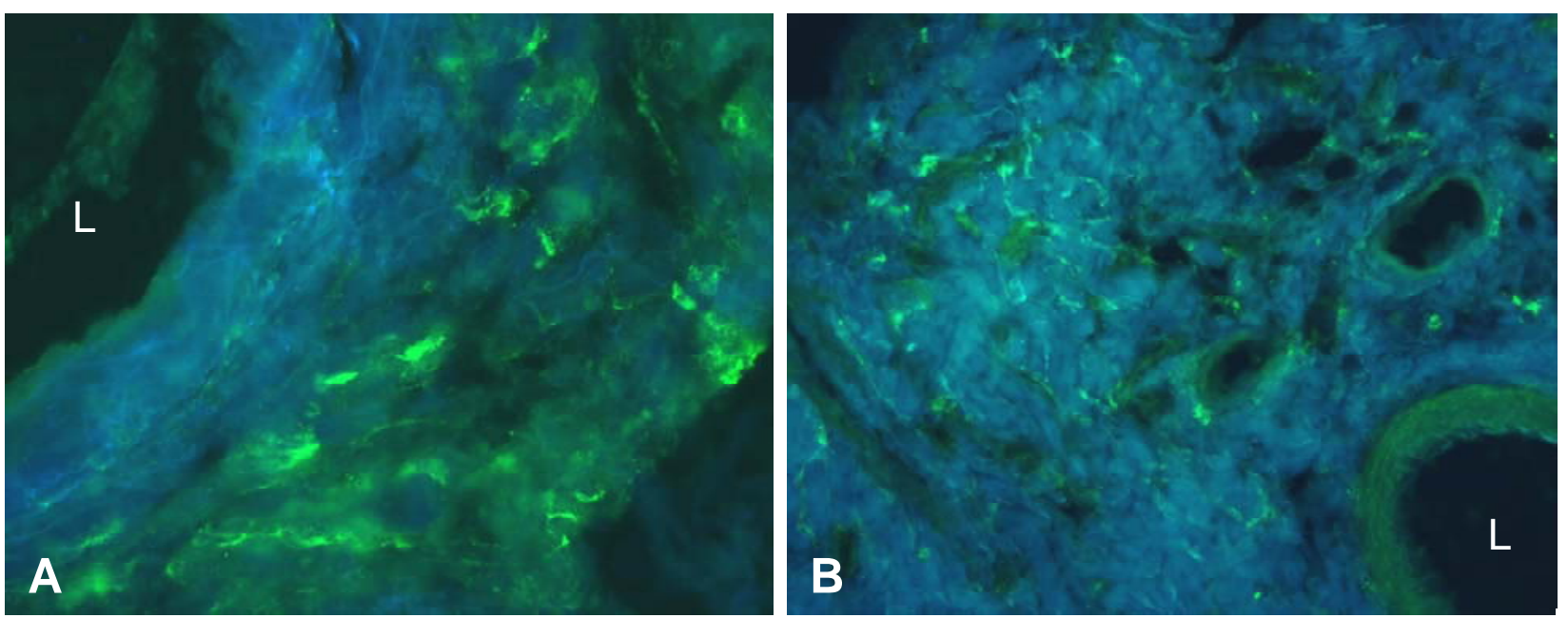

Abbildung 13: Einzelfärbung mit Antikörpern gegen MMP2 an malformierten Venen

A) Bei dieser Vene kann eine deutliche Expression in der Adventitia festgestellt werden. Diese Bereiche sind MMP2-positiv (grün). Lumen der Vene (L). Objektiv-Vergrößerung 20x. B) Auch in dieser malformierten Vene kann man die Expression des Enzyms MMP2 (grün) beobachten. Die positiven Zellen ordnen sich ebenfalls in der Adventitia an. Lumen der Vene (L). ObjektivVergrößerung 20x.

In den untersuchten normalen Venen kann praktisch keine Expression von MMP2 beobachtet werden (Abb. 12). Die malformierten Venen zeigen im Bereich der Adventitia der Gefäße eine vermehrte Bildung dieses Enzyms (Abb. 13) Dies lässt auf einen Umbau des Gewebes, möglicherweise im Zuge einer Entzündung schließen.

\subsection{Immunfluoreszenz-Mehrfachfärbungen}

Um die malformierten Gefäße weiter zu charakterisieren und Hinweise auf eine Veränderung in ihrem Aufbau oder ihrer Aufgabe im Körper zu erhalten, habe ich arterielle (EphrinB2 und EphB2) und venöse Marker (EphB4 und PAL-E) verwendet. Diese habe ich in Kombination mit anti-CD31 Antikörpern und Dapi eingesetzt, um die genaue Lokalisation der möglichen Veränderungen zu bestimmen und um die möglichen Dysregulationen im Aufbau der Gefäße besser lokalisieren zu können.

EphrinB2 ist ein Ligand für Eph-Rezeptoren und ein molekularer Marker für das arterielle Endothel in der embryonalen Angiogenese. Sein TyrosinkinaseRezeptor EphB4 markiert hingegen das venöse Endothel (Gale et al. 2001). Der 
EphB2 Tyrosinkinase Rezeptor bindet ebenfalls an den Liganden EphrinB2 und spielt wie EphB4 eine wichtige Rolle bei der Entwicklung des Gefäßsytems. EphB2 wird hauptsächlich im Endothel arterieller Gefäße exprimiert (Diehl et al. 2005).

PAL-E (Pathologische Anatomie Leiden-Endothelium Antikörper) ist ein spezifischer endothelialer Antikörper (IgG2a), der kleine Gefäße und Venen markiert, jedoch keine Arterien (Schlingemann et al. 1985).

Dapi (4',6-Diamidino-2-phenylindol) ist ein fluoreszierender Farbstoff, welcher in Zellhomogenaten kleinste Nanogramm-Mengen an DNA binden kann (Brunk et al. 1979) und somit zum Nachweis von Zellkernen in der Immunhistologie verwendet wird.

\section{Doppelfärbung mit PAL-E und EphB4}

Die Doppelfärbung mit den venösen Markern EphB4 und PAL-E wurde verwendet, um die venösen Malformationen mit den Venae saphenae magnae $\mathrm{zu}$ vergleichen und um herauszuarbeiten, ob es eine normale Expression der venösen Marker in dem Gefäßendothel der malformierten Vene gibt. 

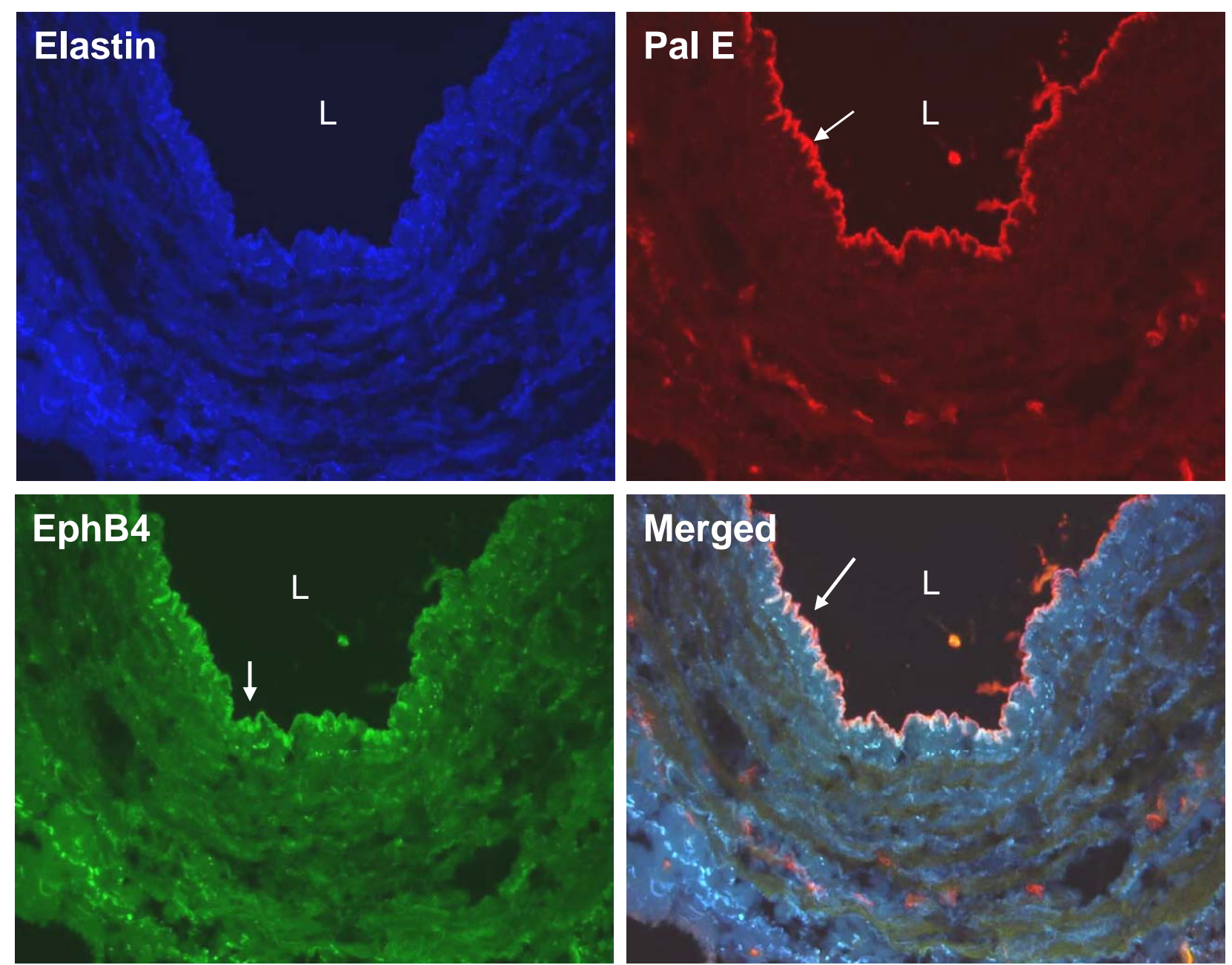

Abbildung 14: Doppelfärbung mit Antikörpern gegen PAL-E und EphB4 an einer normalen Vena saphena magna

Elastin stellt sich in der Abbildung blau dar, PAL-E rot und EphB4 grün. Das Endothel der Vene ist deutlich PAL-E-positiv (Pfeil) und EphB4-positiv (Pfeil). In der Abbildung Merged sind die beiden Antikörper und Elastin zusammen dargestellt, wobei sich das Endothel doppelt-positiv (gelb-rosa) (Pfeil) zeigt (PAL-E und EphB4 kolokalisieren). Objektiv-Vergrößerung 20x. Modifiziert aus: Ebenebe et al. 2007, S. 769. 

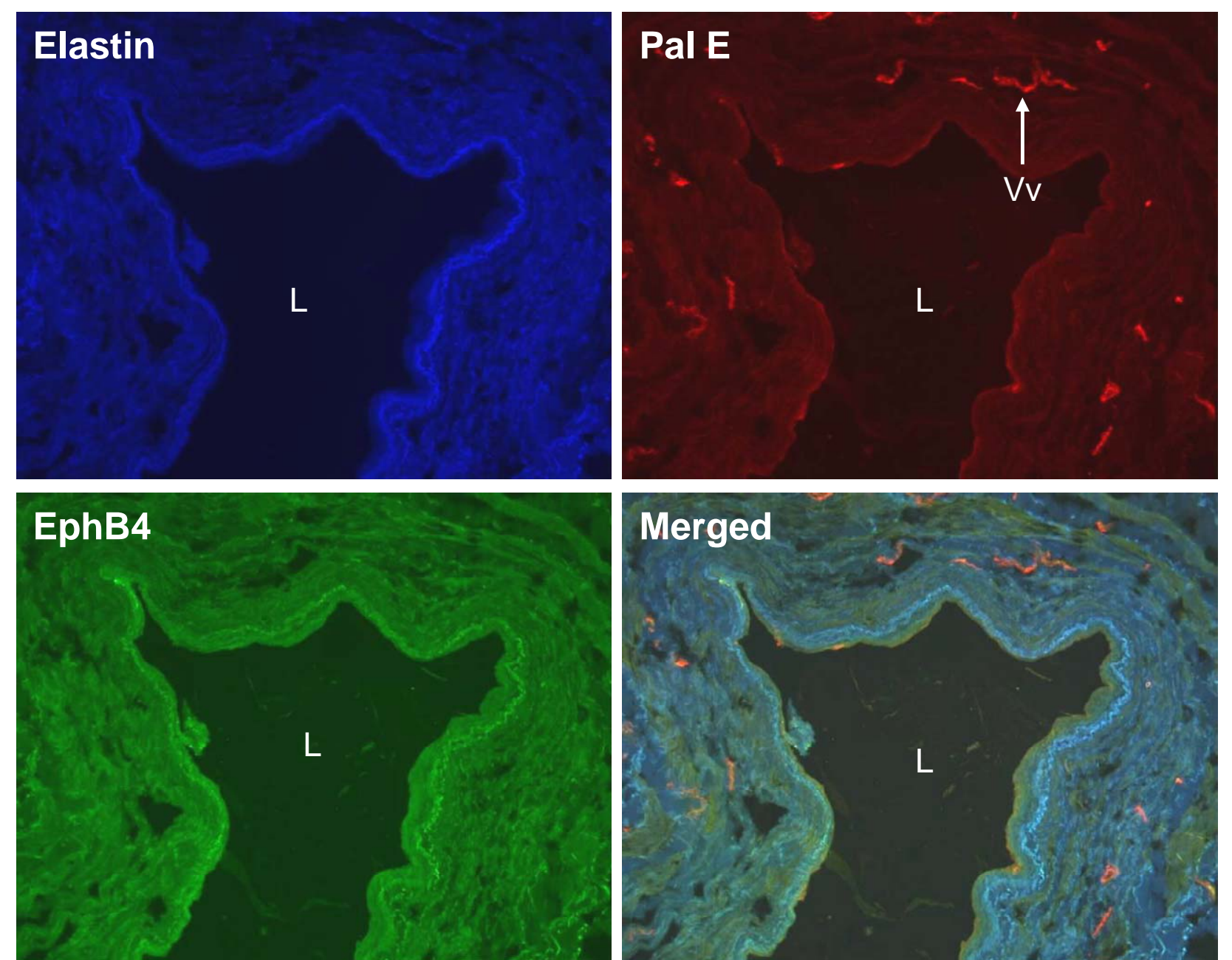

Abbildung 15: Doppelfärbung mit Antikörpern gegen PAL-E und EphB4 an einer malformierten Vene

Elastin stellt sich in der Abbildung blau dar, PAL-E rot und EphB4 grün. In der Abbildung Merged sind die beiden Antikörper und Elastin zusammen dargestellt. Einige Vasa vasorum $(\mathrm{Vv})$ sind PAL-E-positiv. EphB4-Expression ist nicht vorhanden. Lumen der Vene (L). ObjektivVergrößerung 10x. Modifiziert aus: Ebenebe et al. 2007, S. 769. 


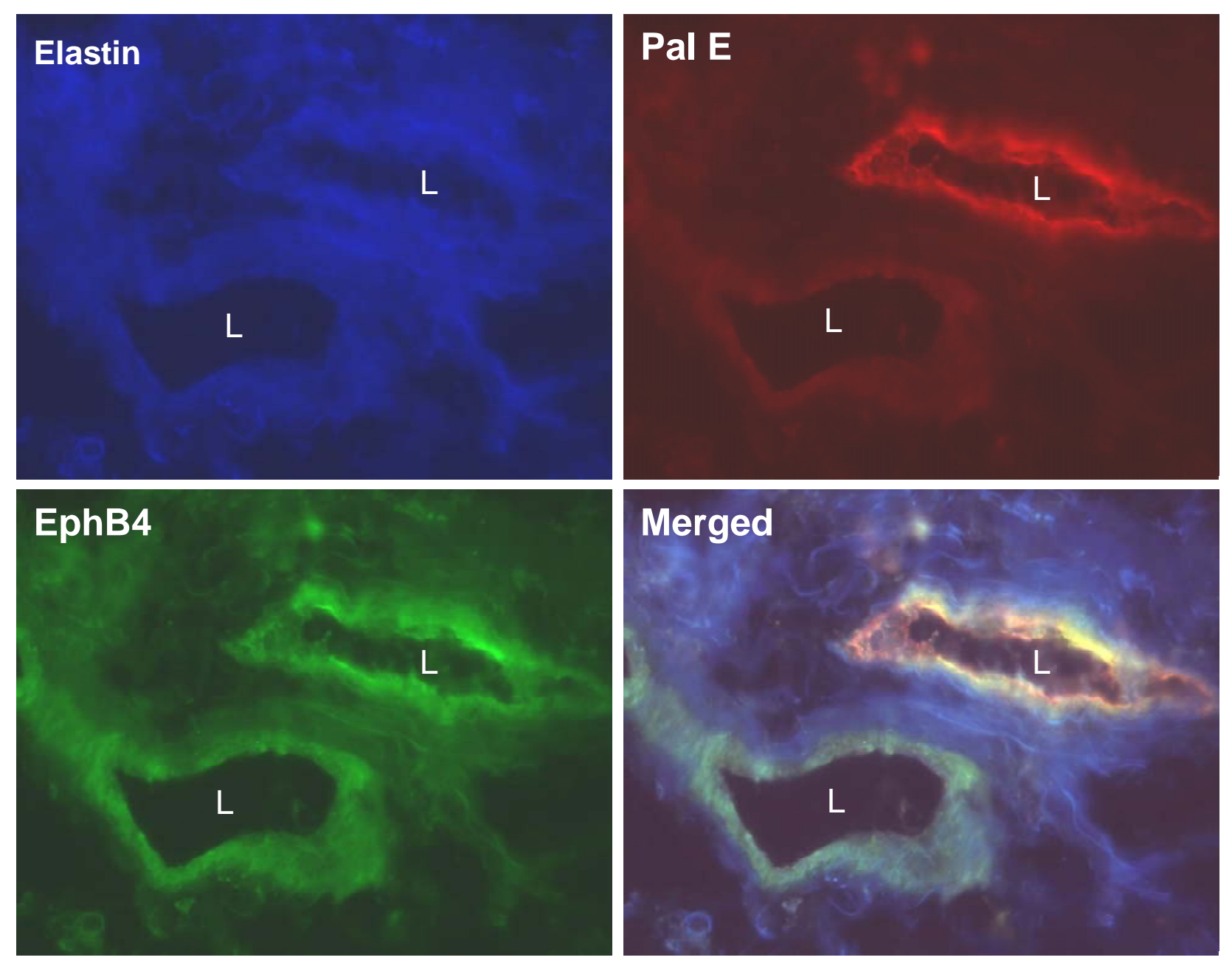

Abbildung 16: Doppelfärbung mit dem Antikörper PAL-E und EphbB4 an einer malformierten Vene

Elastin stellt sich hier blau dar, während PAL-E rot und EphB4 grün sind. In der Abbildung Merged sind beide Antikörper mit Elastin dargestellt. Diese Abbildungen zeigen die Heterogenität mittelgroßer Venen bei venöser Malformation. Die obere der beiden abgebildeten Venen weist in ihrem Endothel den Marker PAL-E (rot) und EphB4 (grün) auf und die untere Vene nur EphB4 (grün). Lumen (L). Objektiv-Vergrößerung 40x.

EphB4 und PAL-E als venöse Endothelmarker werden von den normalen Venen auf deren Endothel-Oberfläche exprimiert (Abb. 14). Beim Endothel der malformierten Venen sieht man eine deutliche Reduzierung des venösen Markers EphB4 und fast keine Expression des venösen Markers PAL-E (Abb. 15, 16). 


\section{Doppelfärbung mit PAL-E und EphrinB2 sowie CD31 und EphrinB2}

In der Doppelfärbung mit PAL-E und EphrinB2 ging es darum, anhand des arteriellen Markers EphrinB2 und des venösen Markers PAL-E darzustellen, inwieweit die malformierten Venen im Vergleich zur normalen Vena saphena magna verändert sind. Die Doppelfärbung mit CD31 und EphrinB2 sollte Aufschluss über die Lokalisation einer möglichen EphrinB2 Synthese geben.
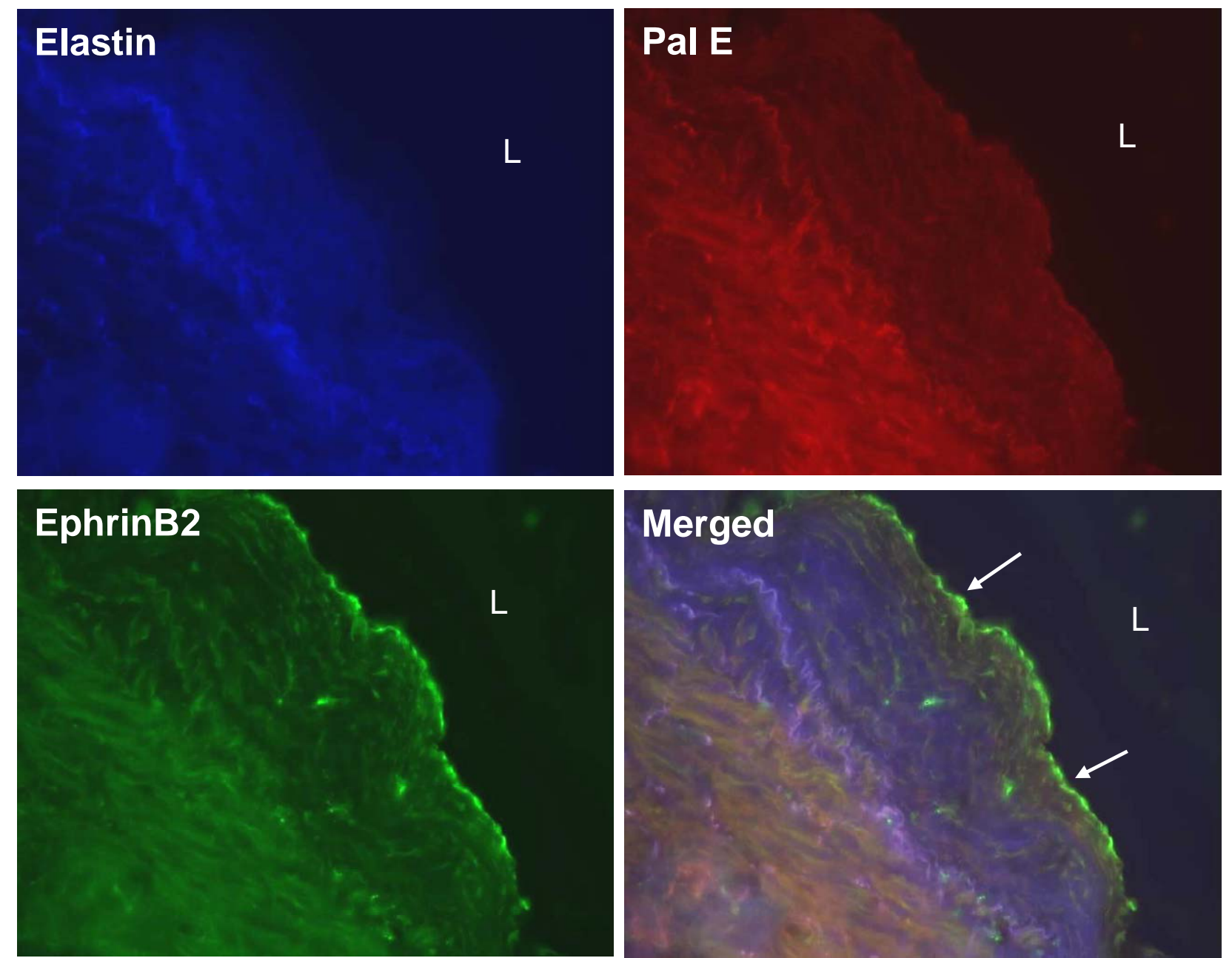

Abbildung 17: Doppelfärbung mit Antikörpern gegen EphrinB2 und PAL-E an einer malformierten Vene

Elastin stellt sich hier blau dar, während PAL-E rot und EphrinB2 grün sind. In der Abbildung Merged sind beide Antikörper mit Elastin dargestellt. Man kann beobachten, dass der venöse Marker PAL-E herunterreguliert ist und im Gegensatz dazu der arterielle Marker EphrinB2 im Endothel der malformierten Vene (Pfeile) deutlich erhöht ist. Lumen der Vene (L). ObjektivVergrößerung 40x. Modifiziert aus: Ebenebe et al. 2007, S. 769. 

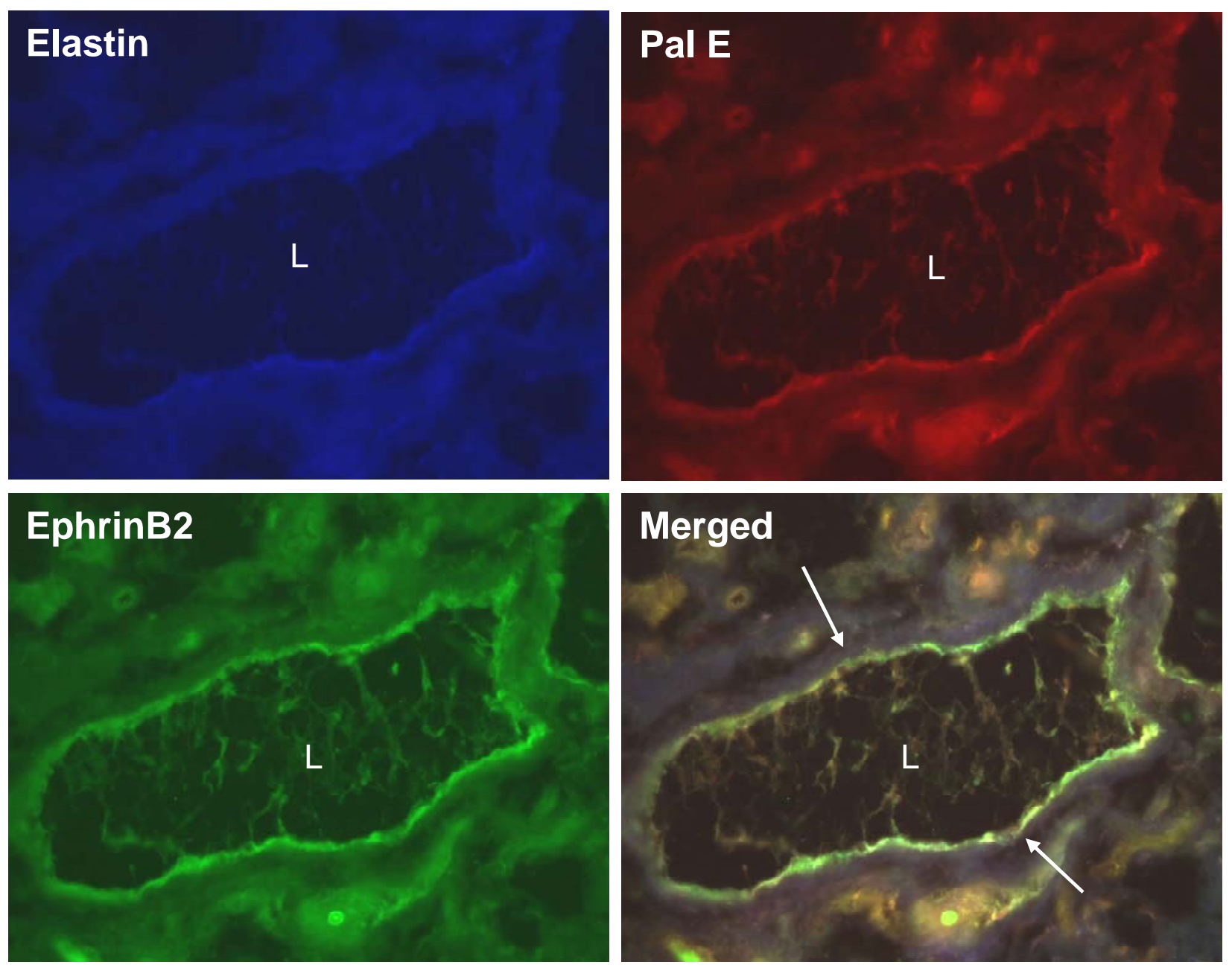

Abbildung 18: Doppelfärbung mit den Antikörpern gegen EphrinB2 und PAL-E an einer malformierten Vene

Elastin stellt sich hier blau dar, während PAL-E rot und EphrinB2 grün sind. In der Abbildung Merged sind beide Antikörper mit Elastin dargestellt. Deutlich positives EphrinB2-Signal in der Abbildung Merged (grün, Pfeile) zeigt das „Arterialisieren“ der malformierten Vene. Lumen (L). Objektiv-Vergrößerung 20x. 

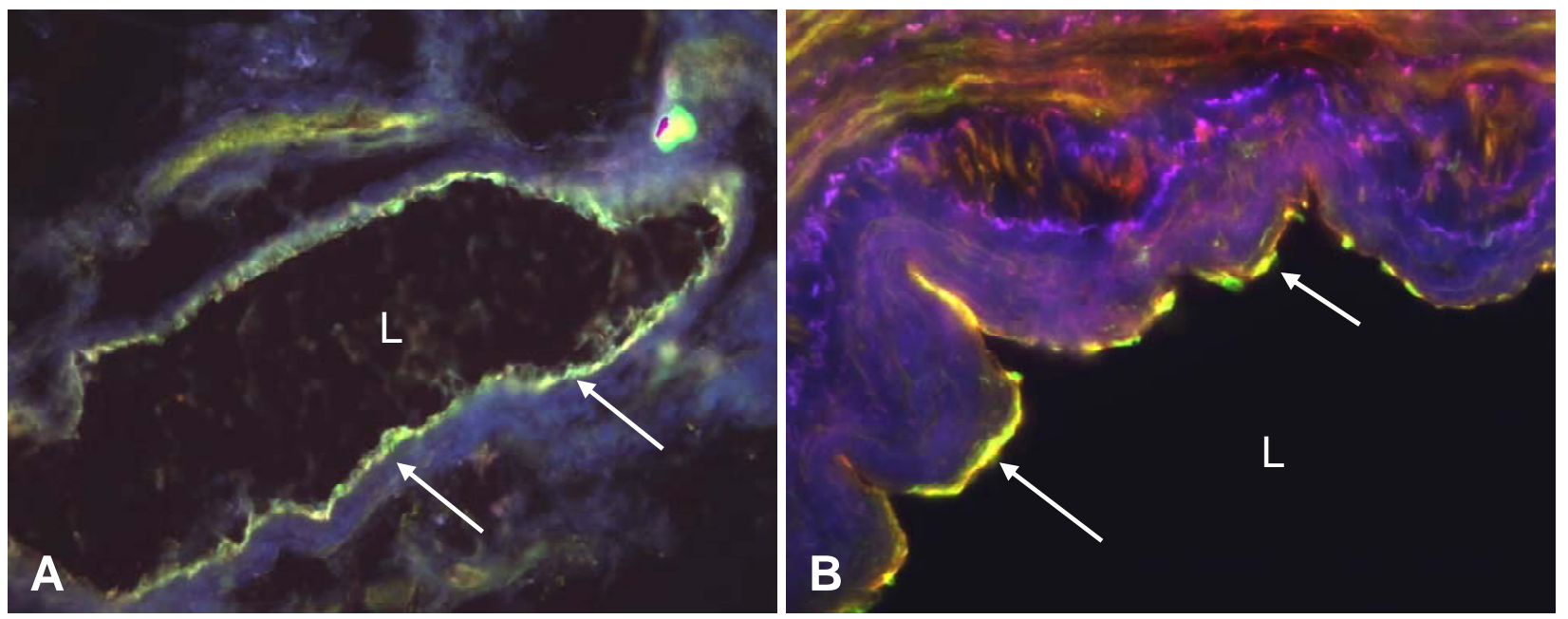

Abbildung 19: Doppelfärbungen mit den Antikörpern gegen CD31 und EphrinB2 an malformierten Venen

A, B) In beiden Venen zeigt sich ein positives EphrinB2- und CD31-Signal im Endothel (gelb, Pfeile) A) Lumen (L). Objektiv-Vergrößerung 20x. B) Lumen (L). Objektiv-Vergrößerung 40x.

Man kann eindeutig eine hohe Expression von EphrinB2 im Endothel der malformierten Venen erkennen (Abb. 17, 18). Die Koexpression von EphrinB2 und CD31 beweist die endotheliale Lokalisation von EphrinB2 (Abb. 19). Das Ergebnis lässt auf eine Arterialisierung des Endothels schließen. PAL-E als venöser Marker scheint in den malformierten Venen herab reguliert zu sein im Vergleich zu den normalen Venae saphenae magnae (Abb. 14), während der arterielle Marker EphrinB2 herauf reguliert ist.

\section{Mehrfachfärbung mit CD31, Dapi und EphB2}

Bei der Mehrfachfärbung mit CD31, Dapi und EphB2 wurde untersucht, ob dieser arterielle Marker in malformierten Venen exprimiert wird. Die Färbung mit CD31 und Dapi dient der Orientierung im Gewebeschnitt und der Frage der Kolokalisation im Endothel. 

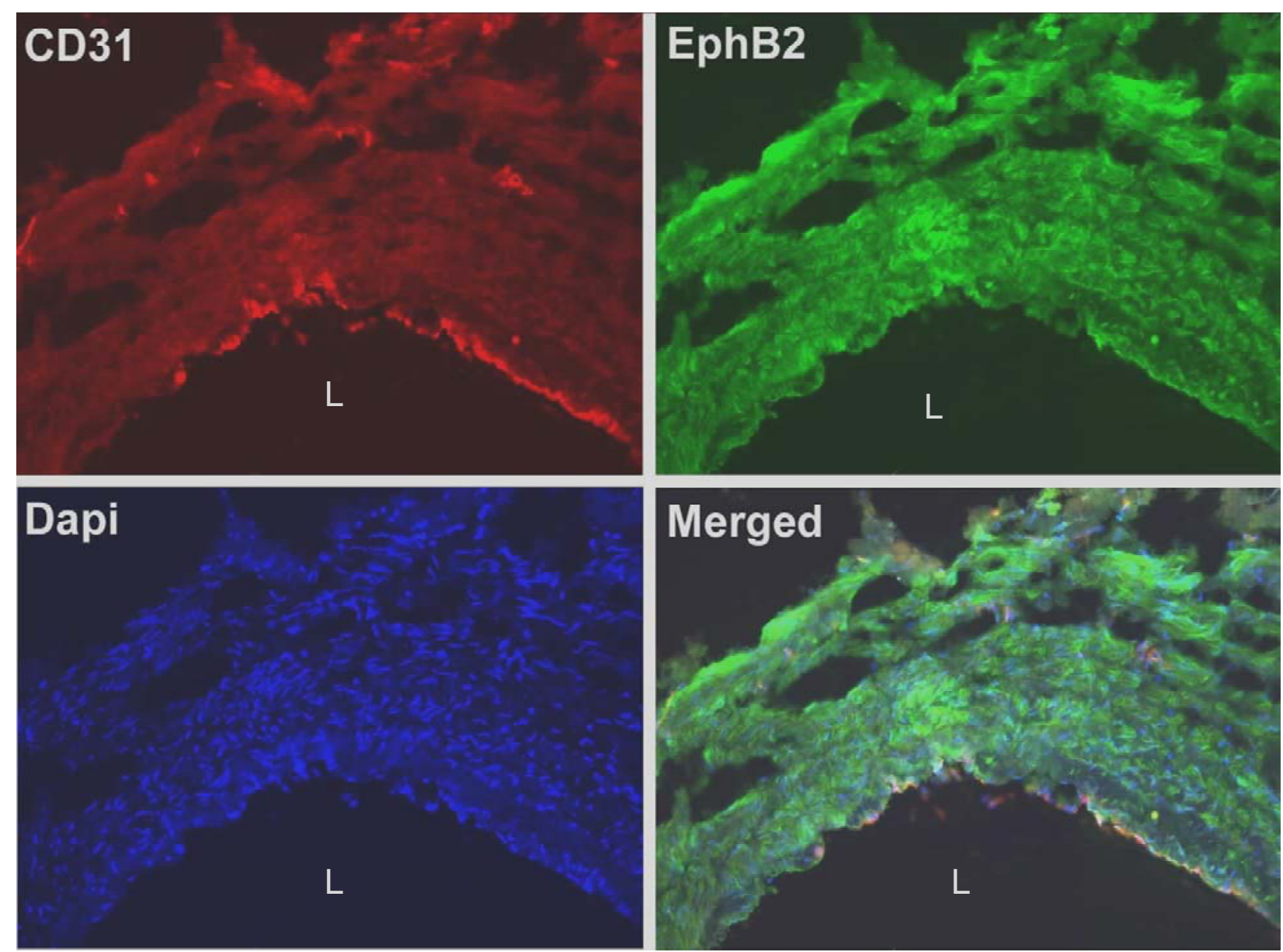

Abbildung 20: Mehrfachfärbung mit Antikörpern gegen CD31 und EphB2 an einer normalen Vena saphena magna

CD31 stellt sich in der Abbildung rot dar, EphB2 grün und Dapi blau. In der Abbildung Merged sind die drei Farben zusammen dargestellt. Das Endothel der Vene ist CD31-positiv (rot) und minimal EphB2-positiv (grün). In der Muskulatur der Tunica media der Vene erkennt man EphB2-positive Anteile und ebenfalls in der Intima, wahrscheinlich in den glatten Muskelzellen. Lumen der Vene (L). Objektiv-Vergrößerung 20x. 

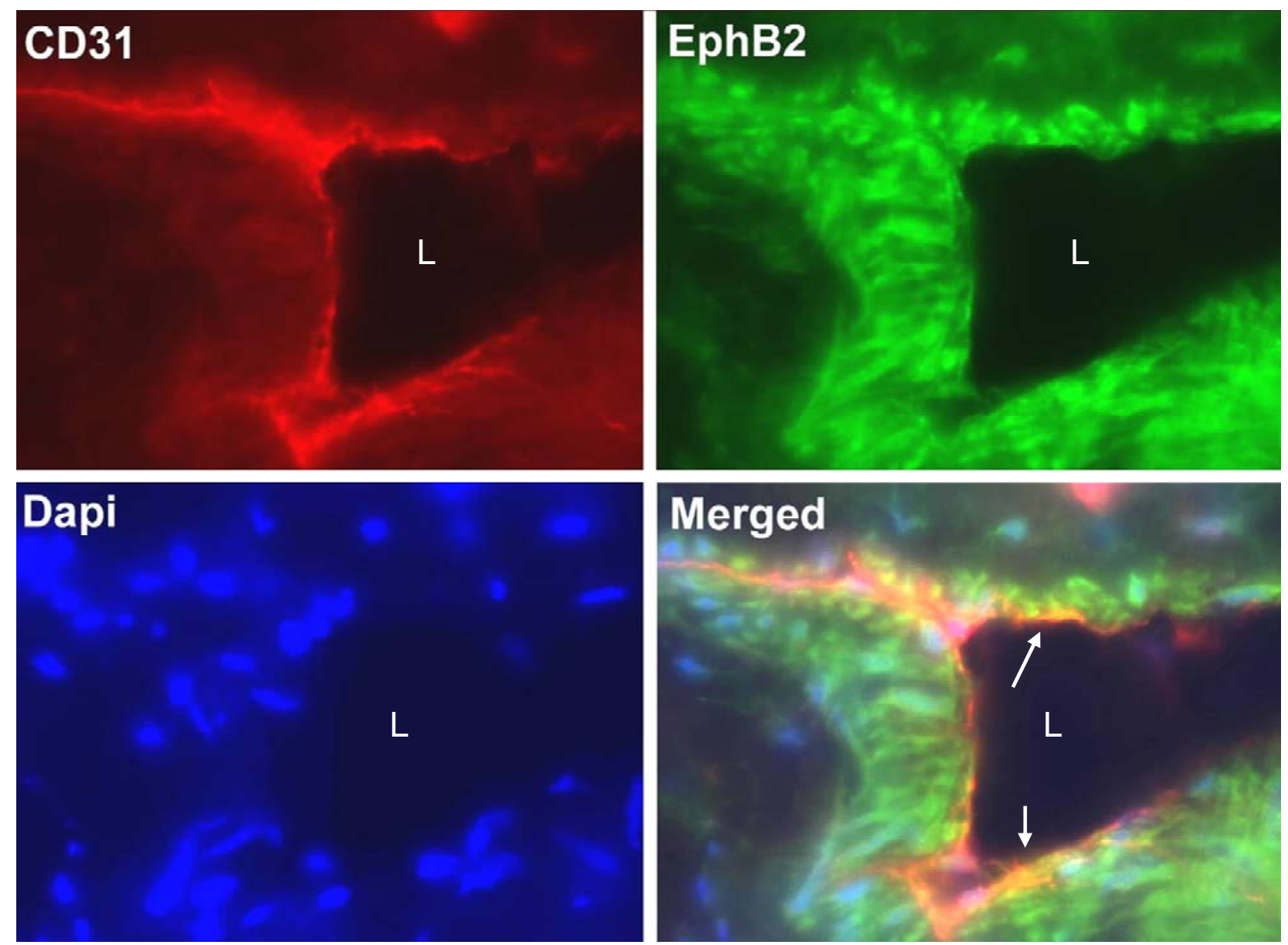

Abbildung 21: Mehrfachfärbung mit Antikörpern gegen CD31 und EphB2 an einer malformierten Vene

CD31 stellt sich in der Abbildung rot dar, EphB2 grün und Dapi blau. In der Abbildung Merged sind die drei Farben zusammen dargestellt, wobei das Endothel hier teilweise doppelt-positiv (gelb) (Pfeile) dargestellt ist (CD31 und EphB2 übereinander gelagert). EphB2 (grün) ist ebenfalls in den Myozyten der Tunica media positiv. Die Zellkerne der verschiedenen Zellen von der normalen und malformierten Vene stellen sich blau dar und das Endothel rot.

Lumen der Vene (L). Objektiv-Vergrößerung 100x.

In den malformierten Venen fällt eine deutlichere Expression des arteriellen Markers EphB2 im Endothel der Vene und in den Myozyten der Tunica media auf, während in der normalen Vene eine Expression von EphB2 vereinzelt in der Muskulatur der Tunica media sowie in der in den glatten Muskelzellen der Intima beobachtet werden kann (Abb. 20, 21). Eine EphB2-Expression im Endothel der normalen Vene ist im geringen Maße auch zu erkennen. 


\subsection{Zusammenfassung der Ergebnisse}

Durch die Untersuchung von malformierten Venen und deren Vergleich mit normalen Venae saphenae magnae konnten einige wesentliche Unterschiede heraus gearbeitet werden.

Die untersuchten malformierten Venen zeigen eine deutliche Zunahme der Vasa vasorum in der Tunica media der Gefäße (Abb. 3), während sich bei den normalen Venen die Vasa vasorum hauptsächlich in der Adventitia befinden (Abb. 2). Durch das Einsprossen der Vasa vasorum in tiefer gelegene Schichten kann es zu Aussackungen der Gefäße und Instabilität kommen.

Die Bündelung der Muskulatur der malformierten Venen ist aufgelockert. Manche Gefäßabschnitte sind muskelschwach ausgebildet (Abb. 5). Die untersuchten normalen Venae saphenae magnae zeigen eine geordnete Muskelbündelung (Abb. 4). Die Muskelauflockerung in den malformierten Venen kann ebenfalls ein Grund für Instabilität im Gefäß sein. Die Vasa vasorum der malformierten Venen zeigen in der Immunfluoreszenz mit Antikörpern gegen unterschiedliche Entzündungsmarker einen Anstieg der Expression. CD54 (Abb. 7), CD62e (Abb. 9) und CD105 (Abb. 11) sind in den Vasa vasorum der kranken Venen deutlich erhöht, was für eine Entzündungsreaktion im Bereich der Adventitia und Tunica media spricht. Das Enzym MMP2, welches ebenfalls vermehrt in den malformierten Venen synthetisiert wird, spricht für einen Gewebeumbau im Bereich der Adventitia und Tunica media (Abb. 13).

Als weiteres Merkmal der malformierten Venen fällt eine Arterialisierung der Gefäße auf. Die arteriellen Marker EphrinB2 und EphB2 sind hier deutlich hoch reguliert (Abb. 17, 18, 19, 21), während die venösen Marker PAL-E und EphB4 herunter reguliert sind (Abb. 15, 16). 
Insgesamt kann man eine Auflockerung der malformierten Gefäße durch das Eindringen der Vasa vasorum in tiefer gelegene Gefäßabschnitte und eine Verminderung und Auflockerung der Muskelbündelung beobachten. Im Bereich der Vasa vasorum kann man Entzündungen und Gewebeumbildung nachweisen und die malformierten Venen weisen Anzeichen einer Arterialisierung auf. 


\section{Diskussion}

In Zentren für vaskuläre Anomalien sind venöse Malformationen die zweithäufigste Einweisungsdiagnose. Die Läsionen treten in der Haut, Mukosa und auch in Muskeln, Knochen und inneren Organen auf. Je nach Lage und Größe können sie anatomische Distorsionen und Schmerz hervorrufen. Diese Form der Erkrankung kann durch Blutungen oder Obstruktionen lebenswichtiger Strukturen zum Tode führen (Boon et al. 2004).

Die meisten venösen Malformationen treten sporadisch auf, jedoch gibt es in einigen Familien den Nachweis einer autosomal dominanten Vererbung. Diese wurden in den Genen TIE2/TEK, KRIT1 und Glomulin identifiziert (Vikkula et al. 1996; Boon et al. 1994; Limaye et al. 2009; Laberge-le Couteulx et al. 1999; Brouillard et al. 2000; Morris et al. 2005).

Es gibt mittlerweile verschiedene Ansätze, venöse Malformationen zu behandeln, wie zum Beispiel eine aktuelle Studie (Pereyra-Rodríguez et al. 2009) zeigt. Man hat gute Erfolge mit sequentieller Applikation von 595nm gepulstem Farblaser und 1064nm Wellenlängen eines Nd:YAG Lasers erzielt. Jedoch ist eine Heilung derzeit noch nicht möglich.

In den durchgeführten Untersuchungen im Rahmen meiner Dissertation habe ich sporadisch auftretende venöse Malformationen von jungen Erwachsenen mit normalen Venae saphenae magnae von Erwachsenen in Hinsicht auf die Expression vaskulärer Moleküle und ihren histologischen Aufbau verglichen.

Die Vergleichbarkeit ist durch den Altersunterschied der Patienten eingeschränkt. Da es aber unmöglich ist, Venen zur immunhistologischen Untersuchung von jungen Erwachsenen $\mathrm{zu}$ erhalten, ist die vorgenommene Untersuchung die bestmögliche. Durch den Altersunterschied können Einflüsse durch das Älterwerden eine Rolle bei der Genexpression und dem Aufbau der 
Venae saphenae magnae spielen, auffällige pathologische Veränderungen waren aber in den Kontrollvenen nicht vorhanden.

\subsection{Aufbau der malformierten Venen}

In meinen Untersuchungen hat sich gezeigt, dass malformierte Venen im Vergleich zu den normalen Venen einen andersartigen Aufbau aufweisen.

Die Zahl der Vasa vasorum ist deutlich vermehrt und sie reichen bis in die Tunica media der Gefäße, während sich die Vasa vasorum der normalen Venen in meinen Untersuchungen und in anderen Studien in der Adventitia befinden (Ritman und Lerman 2007; Williams und Heistad 1996). Dies konnte ich mittels Färbung mit Antikörper gegen CD31 als Endothelmarker besonders gut zeigen. Das Einsprossen der Vasa vasorum in tiefer gelegene Schichten der malformierten Venen kann zur Instabilität der Gefäße führen. Die Instabilität der malformierten Venen kann ebenfalls durch eine vermehrte Bildung des Markers MMP2 (Matrix-Metalloproteinase-2) im Bereich der Adventitia im Zuge eines Umbaus des Gewebes hervorgerufen werden.

Es hat sich ebenfalls gezeigt, dass in den venösen Malformationen die Anordnung der Muskelschicht unstrukturiert, zum Teil vermindert, aufgelockert und zum Teil verdickt erscheint. Ich habe hierzu den Antikörper gegen $\alpha$-Smooth Muscle Actin (SMA) verwendet und konnte im Vergleich dazu den geordneten Wandaufbau der normalen Venen aufzeigen. SMA kann in glatten Muskelzellen, in Perizyten und in Myofibroblasten in den Mikrofilamenten nachgewiesen werden (Skalli et al. 1989).

\subsection{Entzündungszeichen in den venösen Malformationen}

In meinen Untersuchungen habe ich festgestellt, dass Entzündungsmarker im Bereich der Vasa vasorum der malformierten Venen hoch reguliert sind. 
Hierzu habe ich den Antikörper gegen CD54 (ICAM-1/ inter-cellular adhesions molecule-1) verwendet, welcher auf vaskulären Endothelzellen und Leukozyten exprimiert wird. ICAM-1 ist ein Ligand für den Rezeptor LFA-1 (lymphocyte function-associated antigen) (Rothlein et al. 1986). Über diesen Ligand-Rezeptor Komplex können Leukozyten in das Gewebe einwandern (Yang L et al. 2005). CD54 wird bei verschiedenen Krankheiten vermehrt exprimiert, wie zum Beispiel Artherosklerose, Ischämie, venöse Ulzerationen, bei neurologischen Beschwerden, Entzündungen und Malignomen (Lebedeva et al. 2005; Simmons et al. 1988; Pascarella et al. 2005). Meine Untersuchungen zeigen, dass offensichtlich eine Leukozytenmigration im Bereich der Tunica adventitia und der Tunica media stattfindet.

CD62e (ELAM-1/ endothelium leucoyte adhesion molecule-1) ist ein endotheliales Zelladhäsionsmolekül für neutrophile Granulozyten und spielt ebenfalls bei der Extravasation ins umliegende Gewebe eine Schlüsselrolle (Picker et al. 1991; Bevilacqua et al. 1989; Ferrario und Strawn 2006). In einigen malformierten Venen konnte ich eine erhöhte Expression von CD62e in den Vasa vasorum im Vergleich zu den normalen Venen beobachten, welches auf eine erhöhte Extravasation von neutrophilen Granulozyten hinweist.

Um die These zu unterstützen, dass die Entzündungszeichen in den Vasa vasorum erhöht sind, habe ich einen weiteren Antikörper, gegen CD105 (Endoglin), verwendet. CD105 wird auf Endothel und hämatopoetischen Zellen exprimiert und bindet TGF beta Isoformen (Transforming growth factor betaIsoformen). Die Expression ist erhöht bei Wundheilungsstörungen, Angiogenese und Entzündungen (Arthur et al. 2000). In den von mir untersuchten malformierten Venen zeigte sich auch hier eine erhöhte Expression in den Vasa vasorum, welche die vorherigen Befunde nochmals unterstützt. 
Die Untersuchungen mit MMP2 (Matrix-Metalloproteinase-2/ Gelatinase A) zeigte eine vermehrte Expression im Bereich der Tunica adventitia und Tunica media. MMP2 ist ein Enzym, welches physiologischerweise bei der Gewebeneubildung, Embryonalentwicklung, Angiogenese und bei Entzündungen ein Auflösen der Extrazellulärmatrix bewirkt (Zigrino et al. 2001; Nagase et al. 1992). Dies lässt auf Gewebeabbau, -neubildung oder Entzündung schließen.

Meine Untersuchungen belegen die Hochregulation von entzündungsassoziierten Molekülen und stehen im Einklang mit anderen Studien, in denen eine Hochregulation der Chemokine MCP-1 (monocyte chemotactic protein-1) und MCP-2 in malformierten Venen mittels MicroarrayAnalysen nachgewiesen wurde (Ebenebe et al. 2007).

\subsection{Arterialisierung in den venösen Malformationen}

Die Untersuchungen mittels Immunfluoreszenz haben gezeigt, dass arterielle Marker im Endothel der malformierten Venen hoch reguliert und venöse Marker herunter reguliert sind. Hierzu habe ich Doppelfärbungen angefertigt, um den direkten Vergleich zwischen den arteriellen und venösen Markern zu erhalten.

Als arterielle Marker habe ich EphrinB2 und EphB2 verwendet. EphrinB2 ist ein membrangebundener Ligand, der eine entscheidende Rolle übernimmt bei ZellZell-Kontakten. Der EphrinB2 Ligand ist bereits in der frühen Embryonalentwicklung ein molekularer Marker für das arterielle Endothel. Sein Tyrosinkinase-Rezeptor EphB4 markiert hingegen das venöse Endothel. Dies lässt annehmen, dass dieser Ligand-Rezeptor-Komplex bei der Kontaktaufnahme von venösen und arteriellen Gefäßen, zum Beispiel bei Anastomosen, eine Rolle spielt (Gale et al. 2001). Die Eph-TyrosinkinaseRezeptoren werden auch in Zusammenhang gebracht mit verschiedenen 
Formen der Tumorigenese und pathologischen Formen der Angiogenese. Der EphB2-Tyrosinkinase-Rezeptor bindet ebenfalls den Liganden EphrinB2 und spielt wie EphB4 eine wichtige Rolle bei der Entwicklung des kardiovaskulären Systems und Nerven. Man findet zudem oft eine Überexpression von EphB2 Rezeptoren in verschiedenen Tumoren (Chrencik et al. 2007). EphB2 wird hauptsächlich im Endothel arterieller Gefäße exprimiert (Diehl et al. 2005).

In meinen Abbildungen sieht man die deutliche Steigerung der Expression der arteriellen Marker EphrinB2 und EphB2 im Endothel der malformierten Venen im Vergleich zu den normalen Venen. EphB2 ist im Endothel und in den Myozyten der Tunica media und in den normalen Venen in Muskulatur des Gefäßes und den glatten Muskelzellen der Intima zu beobachten. EphrinB2 und der Endothelmarker CD31 weisen eine Koexpression im Endothel der malformierten Venen auf.

Ich habe außerdem den Antikörper PAL-E (Pathologische Anatomie LeidenEndothelium) und anti-EphB4 Antikörper als venöse Marker verwendet. PAL-E ist ein spezifischer endothelialer Antikörper (IgG2a), der Venen und kleine Gefäße markiert, jedoch keine Arterien (Schlingemann et al. 1985). EphB4 wird besonders stark in venösen Gefäßen exprimiert (Wang et al. 1998). Meine Untersuchungen an den malformierten Venen zeigen im Vergleich $\mathrm{zu}$ den normalen Venae saphenae magnae eine deutlich geringere Expression der venösen Markern PAL-E und EphB4.

Die Hochregulation von EphrinB2 und EphB2 weist in den malformierten Venen auf eine Arterialisierung des Endothels hin. In einer anderen Studie wurde gezeigt, dass eine physiologische Arterialisierung in Nabelschnurvenen stattfindet, in denen arterielles Blut von der Plazenta zum Embryo fließt und ebenfalls EphrinB2 im Endothel exprimiert wird (Diehl et al. 2005). Die zusätzliche Abnahme der Expression der venösen Marker PAL-E und EphB4 
deutet auf eine pathologische Arterialisierung in den malformierten Venen hin. Die Ergebnisse der Immunfluoreszenz werden durch Untersuchungen mittels Microarrays bestätigt, in denen EphrinB2 in den malformierten Venen hoch reguliert und EphB4 herunter reguliert ist (Ebenebe et al. 2007).

\subsection{Ergebnisbewertung}

Insgesamt wird hier eine Auswahl von wenigen, jedoch aussagekräftigen immunhistologischen Untersuchungen an venösen Malformationen dargestellt, um so einen generellen Überblick über den Aufbau und die Dysregulation von Genen in den krankhaften Gefäßen zu erhalten. Die Ergebnisse sind sehr aufschlussreich, jedoch sollte man diese Ansätze dazu verwenden, weiterführende Untersuchungen mit mehr Patienten anzufertigen, um die Aussagen zu verifizieren und $\mathrm{zu}$ vertiefen. 


\section{Zusammenfassung}

Die Entstehung venöser Malformationen bei Kindern und jungen Erwachsenen ist noch nicht ausreichend geklärt und wird derzeit weiter untersucht. Anhand genetischer Assoziationsstudien konnten bereits einige Gene identifiziert werden, die mit der Entstehung der Erkrankung in Zusammenhang gebracht werden können, wie zum Beispiel die Gene TIE2/TEK, KRIT1 und Glomulin. Die meisten venösen Malformationen treten jedoch sporadisch auf. Die Diagnose und Behandlung venöser Malformationen machen Fortschritte, eine Kausaltherapie existiert aber nicht.

Jüngste Untersuchungen in unserem Labor haben gezeigt, wie komplex diese Krankheit ist (Ebenebe et al. 2007). In dieser Studie zeigten sich mittels Microarray und PCR Analysen, in Verbindung mit meiner Untersuchung, eine Hochregulation des arteriellen Markers EphrinB2 im Endothel der malformierten Venen sowie eine Herunterregulation der venösen Marker EphB4 und Pal-E. Jedoch konnten 57 Prozent der in den malformierten Venen dysregulierten Gene funktionell nicht zugeordnet werden.

In meinen Untersuchungen habe ich mir mittels Immunfluoreszenz einen Überblick über die Unterschiede der Genexpression malformierter Venen im Vergleich zu normalen Venae saphenae magnae in den Bereichen Struktur, Entzündungszeichen und venöse/arterielle Charakteristika der Gefäße verschafft. Die Ergebnisse zeigen in allen drei Bereichen eine Dysregulation.

$\mathrm{Zu}$ dem ersten Bereich gehört der histologische Wandaufbau der malformierten Venen. In den Untersuchungen mit dem Endothelmarker CD31 zeigt sich, dass die Zahl der Vasa vasorum in den malformierten Venen deutlich erhöht ist. Die Vasa vasorum reichen teilweise bis tief in die Tunica media. In den normalen Venen befinden sich die Vasa vasorum in der Adventitia. Ebenfalls zeigt sich bei der Verwendung des Antikörpers gegen SMA eine unstrukturierte, teils 
verminderte, teils verstärkte Morphologie der Tunica media der malformierten Venen. Diese beiden Komponenten prädisponieren für Gefäßinstabilität und Aussackungen der Gefäße.

Ein weiterer Aspekt meiner Studien zeigt eine Verstärkung der Expression der Entzündungsmarker CD54, CD62e und CD105 in den Vasa vasorum im Bereich der Tunica adventitia und media der malformierten Venen. Die MatrixMetalloproteinase-2 (MMP2), die bei Entzündungen, Angiogenese und Gewebeneubildung vermehrt gebildet wird, ist in den venösen Malformationen in der Tunica adventitia und media ebenfalls erhöht. Dies zeigt, dass Entzündungsmechanismen in den Vasa vasorum eine Teilkomponente der Erkrankung sind.

Der letzte untersuchte Bereich zeigt, dass die malformierten Venen im Endothel eine erhöhte Expression der arteriellen Marker EphrinB2 und EphB2, sowie eine verminderte Expression der venösen Marker PAL-E und EphB4, aufweisen. Dies unterstützt die These, dass es sich hier um eine pathologische "Arterialisierung" des Endothels der malformierten Venen handelt.

Die dargestellten Ergebnisse zeigen, dass venöse Malformationen bei Kindern auf verschiedenen Ebenen hochkomplexe Erkrankungen sind. In allen drei Abschnitten der Gefäße, in der Tunica adventitia, media und interna, sind reaktive Veränderungen nachzuweisen. 


\section{Anhang}

\subsection{Abbildungsverzeichnis}

Abbildung 1: Patient mit malformierten Venen in der unteren Extremität (Quelle: Prof. Dr. D. A. Loose, Hamburg)

Abbildung 2: Einzelfärbungen mit Antikörpern gegen CD31 an normalen Venae saphenae magnae

Abbildung 3: Einzelfärbung mit Antikörpern gegen CD31 an malformierten Venen 27

Abbildung 4: Einzelfärbung mit Antikörpern gegen SMA an einer normalen Vena saphena magna

Abbildung 5: Einzelfärbung mit Antikörpern gegen SMA an malformierten Venen 29

Abbildung 6: Einzelfärbung mit Antikörpern gegen CD54 an normalen Venae saphenae magnae

Abbildung 7: Einzelfärbung mit Antikörpern gegen CD54 an malformierten Venen

Abbildung 8: Einzelfärbung mit Antikörpern gegen CD62e an normalen Venae saphenae magnae

Abbildung 9: Einzelfärbung mit Antikörpern gegen CD62e an malformierten Venen 33

Abbildung 10: Einzelfärbung mit Antikörpern gegen CD105 an normalen Venae saphenae magnae

Abbildung 11: Einzelfärbung mit Antikörpern gegen CD105 an malformierten Venen 35

Abbildung 12: Einzelfärbung mit Antikörpern gegen MMP2 an normalen Venae saphenae magnae

Abbildung 13: Einzelfärbung mit Antikörpern gegen MMP2 an malformierten Venen 37 
Abbildung 14: Doppelfärbung mit Antikörpern gegen PAL-E und EphB4 an einer normalen Vena saphena magna

Abbildung 15: Doppelfärbung mit Antikörpern gegen PAL-E und EphB4 an einer malformierten Vene.....

Abbildung 16: Doppelfärbung mit dem Antikörper PAL-E und EphbB4 an einer malformierten Vene

Abbildung 17: Doppelfärbung mit Antikörpern gegen EphrinB2 und PAL-E an einer malformierten Vene.

Abbildung 18: Doppelfärbung mit den Antikörpern gegen EphrinB2 und PAL-E an einer malformierten Vene 43

Abbildung 19: Doppelfärbungen mit den Antikörpern gegen CD31 und EphrinB2 an malformierten Venen

Abbildung 20: Mehrfachfärbung mit Antikörpern gegen CD31 und EphB2 an einer normalen Vena saphena magna

Abbildung 21: Mehrfachfärbung mit Antikörpern gegen CD31 und EphB2 an einer malformierten Vene 46

\subsection{Tabellenverzeichnis}

Tabelle 1: Eingesetzte Antikörper: Lokalisation, Eigenschaft und Funktion. 


\subsection{Abkürzungsverzeichnis}

Aqua dest.

BSA

CD

Dapi

ELAM-1 / CD62e

FGF

ICAM-1 / CD54 inter-cellular adhesion molecule-1

Ig-Superfamilie Immunglobulin-Superfamilie

$\mathrm{kDa}$

KPP

KRIT1

LFA-1

MCP

MMP2

$\mathrm{n}$

$\mathrm{NaCl}$

PAL-E

PBS destilliertes Wasser

bovine serum albumin

cluster of differentiation

4',6-Diamidino-2-phenylindol

endothelium leukocyte adhesion molecule-1

fibroblast growth factor

kilo-Dalton

Kalium-Phosphatpuffer

krev interaction trapped protein 1

lymphocyte function-associated antigen 1

monocyte chemotactic protein

Matrix-Metalloproteinase-2

Anzahl

Natriumchlorid

Pathologische Anatomie Leiden- Endothelium

phosphate buffered saline 
PECAM-1 / CD31 platelet / endothelial cell adhesion molecule-1

SMA smooth muscle actin

TGF beta transforming growth factor beta

TIE2/TEK tyrosine kinase with Ig and EGF homology domains 2

VEGF vascular endothelial growth factor 


\section{Literaturverzeichnis}

Albelda SM, Oliver PD, Romer LH and Buck CA (1990): EndoCAM: a novel endothelial cell-cell adhesion molecule. J Cell Biol 110:1227-1237.

Altmeyer P, Hoffmann K: Basiswissen Dermatologie: Eine vorlesungsbegleitende Darstellung. 1. Auflage, W3L GmbH, Bochum 2005, 137-138.

Arthur HM, Ure J, Smith AJ, Renforth G, Wilson DI, Torsney E, Charlton R, Parums DV, Jowett T, Marchuk DA, Burn J and Diamond AG (2000): Endoglin, an ancillary TGFbeta receptor, is required for extraembryonic angiogenesis and plays a key role in heart development. Dev Biol 217(1):42-53.

Astner S, Anderson RR (2005): Treating vascular lesions. Dermatol Ther $\underline{18}$ :267281.

Baum U: Anatomie und Physiologie. 7. Auflage, Elsevier, München 2004, 79-91.

Belov S: Classification, terminology and nosology of congenital vascular defects; in: Belov S., Loose DA, Weber J., Hrsg. Vascular Malformations, Einhorn-Presse Verlag, Reinbek 1989, 25-28.

Belov S (1990): Classification of congenital vascular defects. Int Angiol 9:141-146.

Belov S (1993): Anatomopathological classification of congenital vascular defects. Semin Vasc Surg $\underline{6}: 219-224$.

Benninghoff A: Anatomie, Makroskopische Anatomie, Embryologie und Histologie des Menschen, Band 2: Herz-Kreislauf-System, Lymphatisches System, Endokrine Drüsen, Nervensystem, Sinnesorgane, Haut. 16. Auflage, Urban \& Fischer, München 2004, 4-5.

Berenguer B, Burrows PE, Zurakowski D, Mulliken JB (1999): Sclerotherapy of craniofacial venous malformations: complications and results. Plast Reconstr Surg 104(1):1-11, discussion 12-5. 
Bergers G, Benjamin LE (2003): Tumorigenesis and the angiogenic switch. Nat Rev Cancer 3(6):401-10.

Bevilacqua MP, Stengelin S, Gimbrone MA Jr., Seed B (1989): Endothelial leukocyte adhesion molecule 1: an inducible receptor for neutrophils related to complement regulatory proteins and lectins. Science $\underline{243}: 1160-$ 1165.

Boon LM, Mulliken JB, Vikkula M, Watkins H, Seidman J, Olsen BR, Warman ML (1994): Assignment of a locus for dominantly inherited venous malformations to chromosome 9p. Hum Mol Genet $\underline{3}: 1583-1587$.

Boon LM, Mulliken JB, Enjolras O, Vikkula M. (2004): Glomuvenous malformations (glomangioma) and venous malformations. Arch Dermatol 140:971-976.

Brouillard P, Olsen BR, Vikkula M (2000): High-resolution physical and transcript map of the locus for venous malformations with glomus cells (VMGLOM) on chromosome 1p21-p22. Genomics 67(1):96-101.

Brunk CF, Jones KC and James TW (1979): Assay for nanogram quantities of DNA in cellular homogenates. Anal Biochem 92(2):497-500.

Burri PH, Hlushchuk R, Djonov V (2004): Intussusceptive angiogenesis: its emergence, its characteristics, and its significance. Dev Dyn 231(3):47488.

Burrows PE, Laor T, Paltiel H, Robertson RL (1998): Diagnostic imaging in the evaluation of vascular birthmarks. Dermatol Clin 16:455-488.

Buttler K, Kasten P, Wilting J (2009): Molekulare Charakteristika des Lymphangioms beim Säugling. LymphForsch 13(1):22-26.

Carmeliet P, Jain RK (2000): Angiogenesis in cancer and other diseases. Nature 407:249-257.

Chrencik JE, Brooun A, Recht MI, Nicola G, Davis LK, Abagvan R, Widmer H, Pasquale EB and Kuhn P (2007): Three-dimensional structure of the 
EphB2 receptor in complex with an antagonistic peptide reveals a novel mode of inhibition. J Biol Chem 282(50):36505-13.

Cremer H (2005): Vaskuläre Malformationen mit Ähnlichkeit zu vaskulären Tumoren. Phlebologie $\underline{34: 262 .}$

Davis S, Aldrich TH, Jones PF, Acheson A, Compton DL, Jain V, Ryan TE, Bruno J, Radziejewski C, Maisonpierre PC, Yancopoulos GD (1996): Isolation of angiopoietin-1, a ligand for the TIE2 receptor, by secretion-trap expression cloning. Cell 87:1161-1169.

Diehl S, Bruno R, Wilkinson GA, Loose DA, Wilting J, Schweigerer L and Klein R (2005): Altered expression patterns of EphrinB2 an EphB2 in human umbilical vessels and congenital venous malformations. Pediatr Res 57(4):537-44.

Ebenebe C, Diehl S, Bartnick K, Dörge H, Becker J, Schweigerer L, Wilting J (2007): Three reactive compartements in venous malformations. Thromb Haemost 97:763-773.

Edwards PD, Rahbar R, Ferraro NF, Burrows PE, Mulliken JB (2005): Lymphatic Malformation of the Lingual Base and Oral Floor. Plast Reconstr Surg 115:1906-1915.

Enjolras O (1997): Classification and management of the various superficial vascular anomalies: hemangiomas and vascular malformations. J Dermatol 24:701-710.

Ernemann U, Hoffmann J, Grönewaller E, Breuninger H, Rebmann H, Adam C, Reinert S (2003): Hämangiome und vaskuläre Malformationen im Kopfund Halsbereich: Differentialdiagnostik, Klassifikation und Therapie. Radiologe 43:958-966.

Ethunandan M, Mellor TK (2006): Haemangiomas and vascular malformations of the maxillofacial region. Br J Oral Maxillofac Surg 44 $263-272$. 
Ferrario CM, Strawn WB. (2006): Role of the renin-angiotensin-aldosterone system and proinflammatory mediators in cardiovascular disease. Am J Cardiol 98:121-128.

Filston HC (1994): Hemangiomas, cystic hygromas, and teratomas of the head and neck. Semin Pediatr Surg 3(3):147-159.

Fishman SJ, Mulliken JB (1998): Vascular anomalies: a primer for pediatricians. Pediatr Clin North Am 45:1455-1477.

Folkman J (1996): Angiogenesis in cancer, vascular, rheumatoid and other disease. Nat Med 1:27-31.

Folkman J, Shing Y (1992): Angiogenesis. J Biol Chem 267:10931-10934.

Földi M, Földi E, Kubik S: Lymphostatic Diseases; in: Textbook of Lymphology. Urban und Fischer, München 2003, 305.

Fordham LA, Chung CJ, Donnelly LF (2000): Imaging of congenital vascular and lymphatic anomalies of the head and neck. Neuroimaging Clin N Am 10:117-136.

Gale NW, Baluk P, Pan L, Kwan M, Holash J, DeChiara TM, McDonald DM, Yancopoulos GD (2001): Ephrin-B2 selectively marks arterial vessels and neovascularisations sites in the adult, with expression in both endothelial and smooth-muscle cells. Dev Biol 230(2):151-160.

Gallione CJ, Pasyk KA, Boon LM, Lennon F, Johnson DW, Helmbold EA, Markel DS, VikkulaM, Mulliken JB, Warman ML (1995): A gene for familiar venous malformations maps to chromosome $9 \mathrm{p}$ in a second large kindred. J Med Genet 32:197.

Geva E, Ginzinger DG, Zaloudek CJ, Moore DH, Byrne A, Jaffe RB (2002): Human placental vascular development: Vasculogenic and angiogenic (branching and nonbranching) transformation is regulated by vascular endothelial growth factor-A, angiopoietin-1, and angiopoietin-2. J Endocrinol 87:4213-4224. 
Gordon JD, Shifren JL, Foulk RA, Taylor RN, Jaffe RB (1995): Angiogenesis in the Human Female Reproductive Tract. Obstet Gynecol Surv 50:688-697.

Gössl M, Rosol M, Malyar NM, Fitzpatrick LA, Beighley PE, Zamir M, Ritman EL (2003): Functional anatomy and hemodynamic characteristics of vasa vasorum in the walls of porcine coronary arteries. Anat Rec A Discov Mol Cell Evol Biol 272(2):526-537.

Happle R (2006): Kapilläre Malformationen und Molekulargenetik im Jahre 2006: Viel Lärm um nichts? Medgen 18:341-343.

Hawighorst T (2002): Angiogenese, Lymphangiogenese und Tumorprogression. Zentralbl Gynakol 124:497-505.

Hurwitz DJ, Kerber CW (1981): Hemodynamic considerations in the treatment of arteriovenous malformations of the face and sculp. Plast Reconstr Surg 67:421-434.

Iruela-Arispe ML, Dvorak HF (1997): Angiogenesis: a dynamic balance of stimulators and inhibitors. Thromb Haemost 표:672-677.

Joussen AM, Kirchhof B, Gottstein C (2003): Molekulare Mechanismen der Vaskulogenese und Angiogenese. Ophthalmologe 100:284-291.

Juhasz-Böss I, Staede A, Treeck O, Ortmann O, Malik E (2006): Zyklische Expression von Vascular Endothelial Growth Factor (VEGF), Angiopoietin 1 und 2 im Endometrium. Geburtshilfe Frauenheilkd 66:876-881.

Junqueira C, Carneiro J: Histologie. 6. Auflage, Springer Medizin Verlag, Heidelberg 2004, 165-173.

Kaufmann P, Kertschanska S, Frank H-G (2000): Morphologische und zellbiologische Grundlagen der sog. Plazentainsuffizienz. Reproduktionsmedizin 16:405-419.

Kohout MP, Hansen M, Pribaz JJ, Mulliken JB (1998): Arteriovenous malformations of the head and neck: natural history and management. Plast Reconstr Surg 102:643-654. 
Kroll J, Waltenberger J (2000): Regulation der Endothelfunktion und der Angiogenese durch den Vaskulären Endothelialen Wachstumsfaktor-A (VEGF-A). Z Kardiol 89:206-218.

Laberge-le Couteulx S, Jung HH, Labauge P, Houtteville JP, Lescoat C, Cecillon M, Marechal E, Joutel A, Bach JF, Tournier-Lasserve E (1999): Truncating mutations in CCM1, encoding KRIT1, cause hereditary cavernous angiomas. Nat Genet 23(2):189-93.

Lasjaunias PL : Vascular diseases in neonates, infants and children, SpringerVerlag, New York 1997, 445-634.

Lebedeva T, Dustin ML, Sykulev Y. (2005): ICAM-1 co-stimulates target cells to facilitate antigen presentation. Curr Opin Immunol 17: 251-258.

Lee BB, Laredo J, Lee TS, Huh S, Neville R (2007): Terminology and classification of congenital vascular malformations. Phlebology 22:249252.

Limaye N, Boon LM, Vikkula M (2009): From germline towards somatic mutations in the pathophysiology of vascular anomalies. Hum Mol Genet 18:65-74.

Low DW (2003): Management of adult facial vascular anomalies. Facial Plast Surg 19:113-130.

Marler JJ, Mulliken JB (2005): Current management of hemangiomas and vascular malformations. Clin Plast Surg 32:99-116.

Moore K, Persaud TVN, Viebahn C: Embryologie: EntwicklungsstadienFrühentwicklung- Organogenese- Klinik. 5.Auflage, Elsevier, München 2007,$83 ; 365$.

Morris PN, Dunmore BJ, Tadros A, Marchuk DA, Darland DC, D'Amore PA, Brindle NP (2005): Functional analysis of a mutant form of the receptor tyrosine kinase Tie2 causing venous malformations. J Mol Med 83(1):5863. 
Muller WA, Ratti CM, McDonnell SL, Cohn ZA (1989): A human endothelial cell-restricted externally disposed plasmalemmal protein enriched in intercellular junctions. J Exp Med 170:399-414.

Mulliken JB, Fishman SJ, Burrows PE (2000): Vascular anomalies. Curr Probl Surg 37(8):517-520.

Nagase H, Barrett AJ, Woessner JF Jr. (1992): Nomenclature and glossary of the matrix metalloproteinases. Matrix Suppl 1: 421-424.

Nugent MA, Iozzo RV (2000): Fibroblast growth factor-2. Int J Biochem Cell Biol 32:115-120.

O'Reilly MS, Holmgren L, Shing Y, Chen C, Rosenthal RA, Moses M, Lane WS, Cao Y, Sage EH, Folkman J (1994): Angiostatin: a novel angiogenesis inhibitor that mediates the suppression of metastases by a Lewis lung carcinoma. Cell 79:315-328.

O ' Reilly MS, Boehm T, Shing Y, Fukai N, Vasios G, Lane WS, Flynn E, Birkhead JR, Olsen BR, Folkman J (1997): Endostatin: an endogenous inhibitor of angiogenesis and tumor growth. Cell $\underline{88}$ :277-285.

Ornitz DM, Itoh N (2001): Fibroblast growth factors. Genome Biol 2:1-12.

Orten SS, Waner M, Flock S, Roberson PK, Kincannon J (1996): Port-wine stains. An assessment of 5 years of treatment. Arch Otolaryngol Head Neck Surg 122:1174-1179.

Osburn K, Schosser RH, Evert MA (1987): Congenital pigmented and vascular lesions in newborn infants. J Am Acad Dermatol 16:788-792.

Pascarella L, Schonbein GW, Bergan JJ. (2005): Microcirculation and venous ulcers: a review. Ann Vasc Surg 19: 921-927.

Pereyra-Rodríguez JJ, Boixeda P, Pérez-Carmona L, Vañó-Galvan S (2009): Successful treatment of large venous malformation with dual wavelength 595 and 1064 nm system. Photodermatol Photoimmunol Photomed 25(5):283-4. 
Petrova TV, Makinen T, Alitalo K (1999): Signaling via vascular endothelial growth factor receptors. Exp Cell Res 253:117-130.

Picker LJ, Kishimoto TK, Smith CW, Warnock RA, Butcher EC (1991): ELAM-1 is an adhesion molecule for skin-homing T cells. Nature 349:796-799.

Plendl J (2000): Angiogenesis and Vascular Regression in the Ovary. Anat Histol Embryol 29:257-266.

Poole TJ, Coffin JD (1989): Vasculogenesis and angiogenesis: two distinct morphogenetic mechanism establish embryonic vascular pattern. J Exp Zool 251:224-231.

Pratt AG (1953): Birthmarks in infants. AMA Arch Derm Syphilol 67:302-305.

Risau W (1997): Mechanisms of angiogenesis. Nature $\underline{386}: 671-674$.

Ritman EL, Lerman A (2007): The Dynamic Vasa Vasorum. Cardiovasc Res 75(4): 649-658.

Roberts DD (1996): Regulation of tumor growth and metastasis by thrombospondin-1. FASEB J 10:1183-1191.

Rothlein R, Dustin ML, Marlin SD and Springer TA (1986): A human intercellular adhesion molecule (ICAM-1) distinct from LFA-1. J Immunol 137(4):1270-4.

Saaristo A, Karpanen T, Alitalo K (2000): Mechanisms of angiogenesis and their use in the inhibition of tumor growth and metastasis. Oncogene 19:6122-6129.

Schiebler TH, Korf HW: Anatomie: Histologie, Entwicklungsgeschichte, makroskopische und miskroskopische Anatomie, Topographie. 10. Auflage, Steinkopff Verlag, Darmstadt 2007, 178-187; 190-195.

Schlingemann RO, Dingjan GM, Emeis JJ, Blok J, Warnaar SO and Ruiter DJ (1985): Monoclonal Antibody PAL-E specific for endothelium. Lab Invest $\underline{52(1)}: 71-76$ 
Seval Y, Sati L, Celik-Ozenci C, Taskin O, Demir R (2008): The distribution of angiopoietin-1, angiopoietin-2 and their receptors tie- 1 and tie- 2 in the very early human placenta. Placenta 29:809-815.

Shibuya M (2008): Vascular endothelial growth factor-dependent andindipendent regulation of angiogenesis. BMB Reports $\underline{41: 278-286 .}$

Siegert E, Hackert L, Offergeld Ch (2000): Hämangiome und vaskuläre Fehlbildungen - eine interdisziplinäre Aufgabe. Ärztebl Sachsen 11:510513.

Silbernagl S, Despopoulos A: Taschenatlas der Physiologie. 7. Auflage, Stuttgart 2007, 188-190.

Simmons D, Makgoba MW; Seed B (1988): ICAM, an adhesion ligand of LFA-1, is homologous to the neural cell adhesion molecule NCAM. Nature $\underline{313}$ : 624-627.

Skalli O, Pelte MF, Peclet MC, Gabbiani G, Gugliotta P, Bussolati G, Ravazzola M, Orci L. (1989): Alpha-smooth muscle actin, a differentiation marker of smooth muscle cells, is present in microfilamentous bundles of pericytes. J Histochem Cytochem 37(3):315-321.

Spring MA, Bentz ML (2005): Cutaneous vascular lesions. Clin Plast Surg 32:171186.

Tallquist MD, Soriano P, Klinghoffer RA (1999): Growth factor signaling pathways in vascular development. Oncogene 18:7917-7932.

Terman BI, Stoletov KV (2001): VEGF and Tumor Angiogenesis. Einstein Quart J Biol and Med 18:59-66.

van Korlaar I, Vossen C, Rosendaal F, Cameron L, Bovill E, Kaptein A (2003): Quality of life in venous disease. Thromb Haemost 90:27-35.

van Mourik JA, Leeksma OC, Reinders JH, de Groot PG, ZandbergenSpaargaren J (1985): Vascular endothelial cells synthesize a plasma membrane protein indistinguishable from platelet membrane glycoprotein IIa. J Biol Chem 260:11300-11306. 
Vikkula M, Boon LM, Carraway KL, Calvert JT, Diamonti AJ, Goumnerov B, Pasyk KA, Marchuk DA, Warman ML, Cantley LC (1996): Vascular dysmorphogenesis caused by an activating mutation in the receptor tyrosine kinase TIE2. Cell 무:1181-1190.

Wang HU, Chen ZF, Anderson DJ. (1998): Molecular distinction and angiogenic interaction between embryonic arteries and veins revealed by ephrin-B2 and its receptor Eph-B4. Cell 93:741-753.

Williams JK, Heistad DD (1996): Structure and function of vasa vasorum. Trends Cardiovasc Med $\underline{6}: 53-57$.

Wulff C, Weigand M, Kreienberg R, Fraser HM (2003): Angiogenesis during primate placentation in health and disease. Reproduction 126:569-577.

Yakes WF (2004): Endovascular management of high-flow arteriovenous malformations. Semin Intervent Radiol 21:49-58.

Yang L, Froio RM, Sciuto TE, Dvorak AM, Alon R, Luscinskas FW (2005): ICAM-1 regulates neutrophil adhesion and transcellular migration of TNF-alpha-activated vascular endothelium under flow. Blood 106(2):584-92.

Yang WT, Ahuja AT, Metreweli C (1997): Sonographic features of head and neck hemangiomas and vascular malformations. J Ultrasound Med 16:39-44.

Zigrino P, Drescher C, Mauch C (2001): Collagen-induced proMMP-2 activation by MT1-MMP in human dermal fibroblasts and the possible role of alpha2beta1 integrins. Eur J Cell Biol 무:68-77. 


\section{Publikationen im Rahmen dieser Dissertation:}

\section{Original-Publikation}

Chinedu U. Ebenebe, Stefanie Diehl, Katja Bartnick, Hilmar Dörge, Jürgen Becker, Lothar Schweigerer, Jörg Wilting (2007): Three reactive compartments in venous malformations. Thromb Haemost 97:763-773.

\section{Poster}

Ebenebe, Ch.U., Diehl, S., Bartnick, K., Becker, J., Schweigerer, L., Wilting, J.: Dysregulated gene expression in venous malformations. 48. Jahrestagung der Deutschen Gesellschaft für Phlebologie. Rostock, Germany; 4. - 6. Oktober 2006.

Ebenebe, Ch.U., Diehl, S., Bartnick, K., Wilting, J, BeckerJ.: Dysregulated gene expression in congenital venous malformation. 21st Int. Congress of Lymphology. Shanghai, China; 26 - 29. September 2007. 


\section{Danksagung}

Mein besonderer Dank gilt meinem Doktorvater Herrn Prof. Dr. rer. nat. Jörg Wilting für die freundliche Vergabe des Themas und die hervorragende Unterstützung und Betreuung der Arbeit. Seine vielfältigen Anregungen und hilfreichen Kommentare waren für mich sehr wertvoll.

Herrn Dr. Chinedu U. Ebenebe und Frau Dr. Kerstin Buttler danke ich für die freundliche Unterstützung und Zusammenarbeit.

Bei Frau Melanie Böning und bei Herrn Marco Winkler möchte ich mich für die Einarbeitung in die Immunhistologie und ihre Hilfsbereitschaft bedanken.

Von ganzem Herzen möchte ich an dieser Stelle meiner Familie danken, die mich durch alle Höhen und Tiefen des Studiums und der Promotion begleitet hat: meinen Eltern Mary Ann und Alfred, meiner Schwester Jessica, meinen Großeltern Inge und Hans Hirdes sowie meiner Tante Karin und meinem Onkel Eddie.

Ein besonderer Dank gilt meinen Freunden, die mich immer wieder motiviert und stets an mich geglaubt haben. Ohne sie wäre vieles nicht möglich gewesen. 